INRA Prod. Anim., $2005,18(5), 339-354$

\title{
Le clonage somatique : un état des lieux chez les bovins et les petits ruminants
}

\author{
Y. HEYMAN, P. CHAVATTE-PALMER, X. VIGNON, C. RICHARD I, J.-P. RENARD \\ INRA, UMR Biologie du Développement et Reproduction, F-78352 Jouy-en-Josas \\ ${ }^{1}$ UCEA-INRA, Bressonvilliers, F-91630 Leudeville \\ Courriel :yvan.heyman@jouy.inra.fr
}

Le clonage somatique chez les ruminants, aborde une phase de transition entre les travaux de recherche et les premières applications dans les domaines thérapeutiques et agronomiques. Les bovins clonés se développent apparemment de façon normale jusqu'au stade adulte et sont capables de se reproduire par voie sexuée. Ces «nouveaux animaux» et leurs produits, qui sont en cours d'évaluation soulèvent des questions d'éthique et d'acceptabilité sociale du clonage animal.

Chez les animaux d'élevage, le clonage en vue d'obtenir un ensemble d'individus possédant le même génome a été réussi pour la première fois chez le mouton en 1986, par la technique de transfert de noyaux embryonnaires (Willadsen 1986) dans des ovocytes énucléés, puis chez la vache avec la naissance de 8 veaux mâles issus d'un même embryon donneur de noyaux (Bondioli et al 1990). Cependant, les possibilités d'obtention de clones à partir des noyaux d'un jeune embryon sont limitées en raison du faible nombre de noyaux disponibles (une trentaine). Un grand pas a été franchi avec la possibilité d'obtenir un jeune à partir de noyaux de cellules somatiques comme cela a été démontré par la naissance de la brebis Dolly (Wilmut et al 1997). Le clonage somatique consiste, à partir de cellules différenciées qui peuvent être prélevées sur un animal adulte (donc connu) à utiliser ces cellules comme source de noyaux diploïdes qui seront introduits dans des ovules receveurs préalablement débarrassés de leurs propres chromosomes par énucléation. Les séries d'embryons ainsi reconstitués par micromanipulation sont cultivées in vitro avant d'être réimplantés dans des femelles porteuses qui assureront la gestation.

Photo de clones somatiques issus d'une vache donneuse

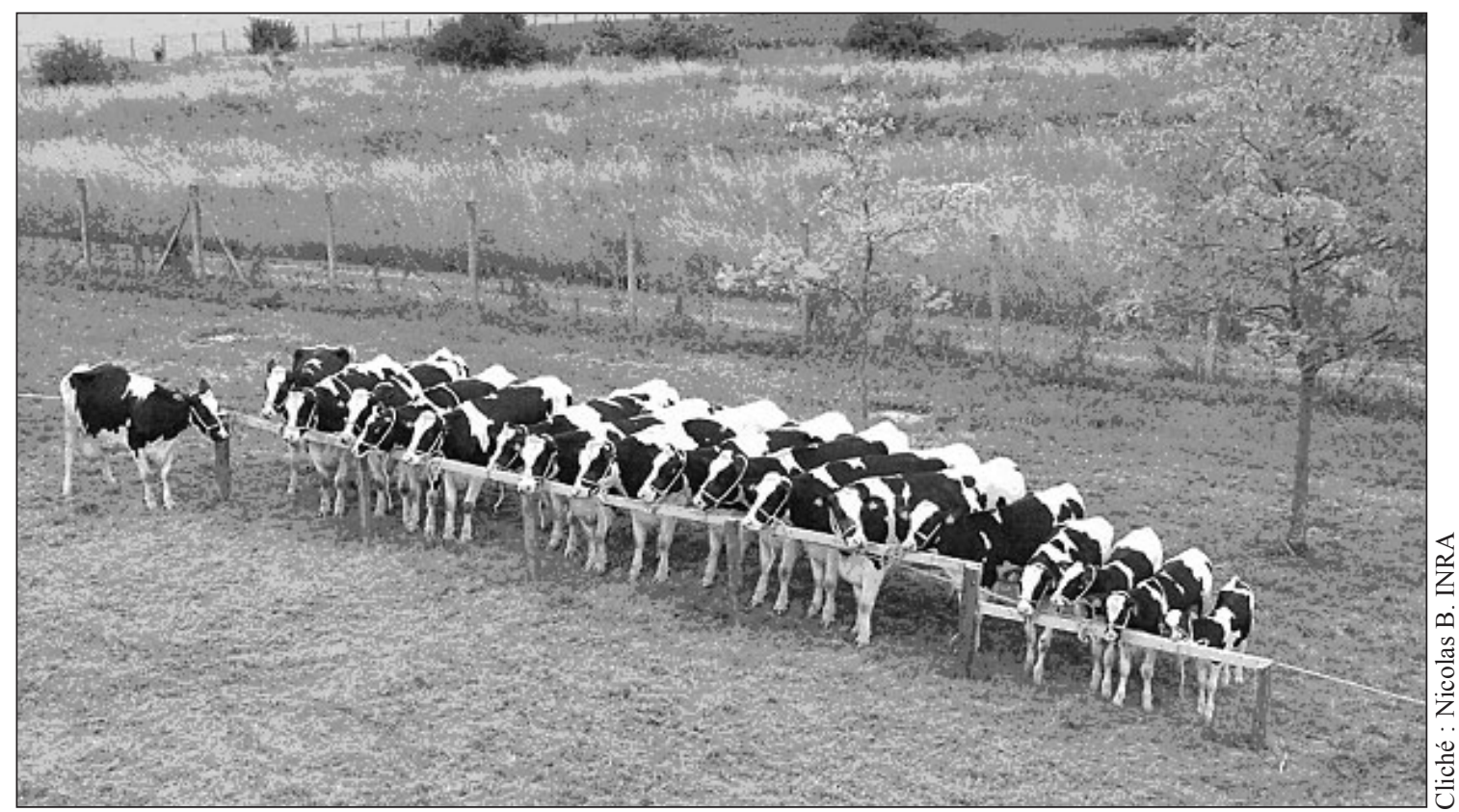

De gauche à droite : la vache $n^{\circ} 38$ (isolée) donneuse de cellules de peau puis ses 17 clones par ordre d'âge décroissant (de 4 ans à 3 mois) 
Dans cet article, nous nous limiterons aux résultats récents obtenus à partir de noyaux somatiques en particulier chez les bovins à l'INRA mais également chez les petits ruminants (mouton et chèvre) qui deviennent des espèces modèles, si l'on associe la modification génétique des cellules au clonage proprement dit. La possibilité d'obtenir des séries d'animaux génétiquement identiques présente de multiples intérêts et nous avions déjà évoqué dans une précédente synthèse parue dans INRA Productions Animales, les applications potentielles du clonage (Colleau et al 1998). Depuis 1997, des clones ont été obtenus chez les principales espèces d'élevage (mouton, vache, chèvre, porc, cheval, lapin). Nous allons tenter d'évaluer l'efficacité actuelle du clonage somatique chez les ruminants, principalement les bovins, espèce la plus utilisée aujourd'hui, ainsi que les caractéristiques des animaux obtenus. Nous traiterons aussi des différents «verrous biologiques» qui font que l'efficacité du clonage reste encore faible.

\section{1 / Résultats actuels du clonage somatique}

\section{1 / Nombre d'animaux obte- nus}

Chez les bovins, rappelons que les premiers veaux issus de clonage somatique dans le monde sont nés en 1998 à quelques jours d'intervalle aux EtatsUnis (Cibelli et al 1998) et en France à l'INRA (Vignon et al 1998). Ce premier veau Français (Marguerite) issu de cellules musculaires prélevées sur un fœtus n'a pas survécu au delà de 2 mois après sa naissance en raison d'une déficience immunitaire majeure associée à une aplasie thymique (Renard et al 1999). Quelques années plus tard, en 2005, on peut estimer à environ 1500 le nombre total de veaux nés à travers le monde d'après les informations rapportées à l'IETS (International Embryo Transfer Society). Le clonage chez les bovins est surtout réalisé en Amérique du Nord (USA/Canada) par quelques grandes compagnies privées (Infigen, Cyagra, Hematech...) ou universités (U Conn, UCLA, Texas A\&M...) qui ont produit à ce jour environ la moitié des clones bovins vivants. Le deuxième pays est certainement le Japon où il existe une trentaine de laboratoires de clonage qui ont produit près de 400 veaux, puis la Nouvelle-Zélande (133 veaux). En Europe, la France a fait naître 72 veaux, tous produits par la seule équipe INRA, en collaboration avec l'UNCEIA, l'Allemagne a obtenu une quarantaine d'animaux à l'Université de Munich, et l'Italie n'a pu produire que quelques bovins en raison d'une réglementation très limitante dans ce pays. Parmi les autres pays ayant obtenu des clones de bovins, il faut mentionner l'Australie et plusieurs pays qui développent actuellement activement ces techniques (Chine, Corée du Sud, Argentine, Brésil...). Les estimations actuelles évolueront rapidement dans les années à venir. En effet, sur les 550 publications scientifiques traitant du clonage depuis 1996, la moitié concernent les bovins et plus de $10 \%$ le porc. Mais la proportion des articles issus des pays asiatiques augmente rapidement et représente en 2005 plus du tiers de ces publications (Whitelaw 2005).

En ce qui concerne les petits ruminants, l'activité de clonage est beaucoup plus faible. Chez les ovins ou caprins, cette technique est surtout associé à la transgénèse, soit pour obtenir des nouveaux modèles pour la recherche biomédicale ou agronomique, soit pour la production de protéines humaines dans le lait ou le sang pour l'industrie pharmaceutique. Le nombre de petits ruminants, moutons et chèvres, nés à travers le monde depuis Dolly ne doit pas dépasser 200 et dans quelques laboratoires seulement. Pour la chèvre, trois laboratoires aux USA et Canada concentrent leur activité sur la production de molécules dans le lait (antithrombine humaine recombinante, vaccin anti-malaria, sérum albumine humaine). Certaines molécules recombinantes comme l'activateur de plasminogène produites par des chèvres clonées et transgéniques sont déjà en phase III d'expérimentation et devraient être introduites sur le marché pharmaceutique prochainement pour traiter les affections coronariennes. Ces molécules peuvent ne pas être exclusivement à usage médical puisque certains projets concernent l'obtention de biomatériaux (Biosteel, Nexia, Canada qui veut faire produire dans le lait de chèvre des protéines constitutives de soie d'araignée). Les clones ovins sont surtout obtenus à partir de cellules fœtales cultivées et transfectées. Des lignées cellulaires ovines ont pu être cultivées suffisamment longtemps pour être modifiées par recombinaison homologue de façon à supprimer le gène de la protéine prion (Denning et al 2001). Les moutons ainsi obtenus par transfert de noyaux de ces cellules pourraient constituer des modèles pour l'étude des pathologies associées à cette protéine prion.

\section{2 / Un rendement encore très variable}

Plusieurs types de cellules somatiques prélevées dans différents tissus ou organes (muscle, peau, ovaire, sang...) ont été utilisés avec succès en transfert de noyaux et ont démontré leur aptitude au développement à terme des embryons reconstitués. Cependant, le rendement peut être très variable selon la source de noyaux utilisés (tableau 1).

Par exemple, les cellules épithéliales de glande mammaire qui ont permis d'obtenir Dolly ne sont pas les plus efficaces car il a fallu reconstituer 277 embryons pour obtenir un agneau (Wilmut et al 1997). Il en est de même chez la vache où ce type de cellule a permis de produire un veau à partir de 223 embryons reconstitués (Zakhartchenko et al 1999). Les cellules donneuses issues du cumulus ovocytaire semblent avoir un potentiel plus important. Elles conduisent à un rendement global de l'ordre de 6-7 \% (nombre de veaux obtenus à partir de 100 cellules somatiques), mais ces cellules ne sont pas d'un accès facile sur l'animal vivant (prélèvement d'ovocytes par Ovum Pick Up sous échographie ou OPU), et sont limitées aux femelles.

Les cellules de peau présentent l'avantage d'être facilement accessibles et leur prélèvement n'est pas traumatisant pour l'animal donneur (biopsie de peau après anesthésie locale). Après mise en culture, la peau permet d'obtenir des lignées cellulaires de type fibroblastes que l'on peut congeler avant leur utilisation comme source de noyaux. Pour ces raisons, les fibroblastes dérivés de la peau constituent la source de cellules la plus utilisée pour le clonage somatique, tout au moins dans l'espèce bovine. L'efficacité globale reste encore faible et très variable $(0,5$ à $7 \%$ de veaux nés par rapport aux embryons reconstitués) selon les laboratoires et peut être l'origine génétique des lignées cellulaires (Oback et Wells 2003, Faber et al 2004, Heyman et al 2004). Chez la vache, nous avons montré qu'en utilisant la même technique de transfert nucléaire, le taux de vêlage à terme après transplantation des embryons clonés pouvait varier de $3 \%$ à $25 \%$ selon l'animal donneur. En effet, nous avons obtenu un clone de 15 femelles Holstein après transplantation de 60 blastocystes développés in 
Tableau 1. Résultats du clonage somatique chez les ruminants avec différents types de cellules donneuses.

\begin{tabular}{|c|c|c|c|c|}
\hline Espèce & $\begin{array}{c}\text { Type de cellules } \\
\text { donneuses } \\
\text { (origine) }\end{array}$ & $\begin{array}{c}\text { in vitro } \\
\text { Blastocystes/ } \\
\text { embryons } \\
\text { reconstitués } \\
\text { (\%) }\end{array}$ & $\begin{array}{c}\text { in vivo } \\
\text { Jeunes } \\
\text { nés/embryons } \\
\text { transplantés } \\
(\%)\end{array}$ & $\begin{array}{c}\text { Rendement } \\
\text { global Jeunes } \\
\text { nés/embryons } \\
\text { reconstitués } \\
(\%)\end{array}$ \\
\hline Bovins & $\begin{array}{l}\text { Fibroblastes } \\
\text { (peau adulte) } \\
\text { Fibroblastes } \\
\text { (peau fœtale) } \\
\text { Muscle } \\
\text { Leucocytes (sang) } \\
\text { Glande mammaire } \\
\text { Cumulus (ovaire) } \\
\text { Granulosa (ovaire) } \\
\text { Epithélium oviducte }\end{array}$ & $\begin{array}{c}12-60 \\
12-47 \\
14 \\
18 \\
17-32 \\
28-42 \\
16-70 \\
21-39\end{array}$ & $\begin{array}{c}5-20 \\
6-87 \\
\\
15 \\
2 \\
4-25 \\
7-83 \\
3-14 \\
12-75\end{array}$ & $\begin{array}{c}0,6-3 \\
0,7-7 \\
\\
<1 \\
0,3 \\
<1 \\
2-5 \\
0,5-2,2 \\
0,8-4\end{array}$ \\
\hline Ovins & $\begin{array}{l}\text { Fibroblastes (fœtus) } \\
\text { Glande mammaire } \\
\text { (adulte) } \\
\text { Granulosa }\end{array}$ & $\begin{array}{c}14-27 \\
11 \\
12-30\end{array}$ & $\begin{array}{c}3-18 \\
3 \\
7\end{array}$ & $\begin{array}{c}0,6-4 \\
0,3 \\
0,8-2,1\end{array}$ \\
\hline Caprins & $\begin{array}{l}\text { Fibroblastes (fœtus) } \\
\text { Cumulus } \\
\text { Granulosa }\end{array}$ & $\begin{array}{l}20-35 \\
\text { ND } \\
\text { ND }\end{array}$ & $\begin{array}{c}2-13 \\
1,3 \\
7,5\end{array}$ & $\begin{array}{c}1-3 \\
<1 \\
7\end{array}$ \\
\hline
\end{tabular}

(Données non exhaustives d'après résultats publiés).

vitro alors que 2 veaux seulement sont nés après transplantations de 85 blastocystes issus d'un autre animal donneur de même race. Cependant, pour un même génotype, l'efficacité du clonage peut dépendre de la lignée cellulaire et du nombre de passages en culture in vitro (Vignon 2003).

\section{3 / Une efficacité qui progresse}

Au cours des cinq dernières années, les résultats du clonage somatique chez les ruminants ont nettement progressé si l'on en juge par le nombre d'équipes impliquées à travers le monde et le nombre de jeunes nés, même si le rendement reste encore faible. Les progrès les plus sensibles ont été obtenus pour le développement in vitro des embryons reconstitués : les taux de blastocystes après transfert de noyaux sont maintenant de l'ordre de 30 à $50 \%$ alors qu'ils étaient inférieurs à $10 \%$ il y a 5 ans. Ceci est dû à une meilleure maîtrise des conditions de reconstitution (cycle cellulaire, activation, culture in vitro...). En revanche, les taux de gestation à terme sont encore limités par des mortalités importantes (voir plus loin) et n'ont que peu progressé pendant la même période.

Globalement, nous pouvons considérer qu'en moyenne le rendement (nombre de jeunes nés/nombre d'embryons reconstitués) du clonage somatique chez les bovins a triplé depuis 1998. On constate ainsi une évolution semblable, quoique plus lente, à celle qui a prévalu avec la transplantation d'embryons issus de fécondation in vitro chez les bovins il y a une dizaine d'années. Ces améliorations reposent essentiellement sur la maîtrise de la chaîne technique requise pour aboutir à la production de blastocystes transplantables. La logistique est largement commune aux activités de fécondation in vitro et de clonage quoique plus complexe pour cette dernière. Il est alors frappant de constater que les meilleurs rendements annoncés, supérieurs en moyenne à $10 \%$ chez les bovins et chez le porc, sont obtenus par les laboratoires qui ont pu réunir les moyens financiers pour associer à l'activité de clonage une démarche qualité permettant d'optimiser les nombreux paramètres techniques de la filière (Faber et al 2004, Scott 2005).

\section{4 / Des mortalités embryonnai- res et foetales importantes}

Le développement in vivo après transplantation des blastocystes clonés dans l'utérus de la porteuse est caractérisé par des pertes embryonnaires importantes pendant la période périimplantatoire puis des pertes plus tardives (Heyman et al 2002), associées à une pathologie spécifique: le «Large Offspring Syndrome» ou LOS (Young et al 1998). Ce sont ces perturbations tardives de la gestation qui constituent actuellement la principale limite au clonage, non seulement sur le plan économique en raison du coût des receveuses mais également sur le plan éthique, car ces pathologies fœetales peuvent affecter le bien-être du fotus et celui de la porteuse dont les risques de mise bas par césarienne sont accrus.

\section{a) Période péri-implantatoire}

L'établissement de la gestation après transplantation d'embryons clonés peut être suivi d'abord par le dosage de la progestérone plasmatique chez la porteuse (diagnostic de gestation à J21) puis par des échographies répétées afin de confirmer la présence d'un fœtus vivant. Chez les bovins, on peut considérer que le taux de gestations initiées, estimé par le taux de DG positifs à 21 jours, n'est pas significativement différent pour les embryons clonés ou les embryons issus de FIV (55 à $65 \%$ ).

Cependant dès le premier contrôle échographique à 35 jours, on constate une réduction de l'ordre de $30 \%$ chez les clones (figure 1). Dès ce stade et même avant, on constate un retard dans le développement placentaire et fœtal (Hill et al 2000, De Sousa et al 2001). A l'INRA, nous avons mesuré la taille des placentomes et des fotus chez les porteuses de clones à 35,50 et 63 jours de gestation et observé que ces mesures sont significativement plus faibles chez les clones par rapport à des génisses témoins gestantes après IA (Laigre et al 2004). Ces retards dans le développement placentaire sont associés à des perturbations de la vascularisation (Hill et al 2000) et pourraient être la cause d'une partie de ces pertes périimplantatoires. De plus, le traitement des embryons in vitro avant transfert peut entraîner des différences. En effet, les taux d'implantation sont réduits quand les embryons clonés sont issus de cellules génétiquement modifiées par transfection (Forsberg et al 2002). L'examen du placenta des porteuses de clones a montré des anomalies d'expression des antigènes de classe I du complexe majeur d'histocompatibilité (MHC1) qui pourraient aussi être à l'origine de ces pertes précoces (Hill et al 2002).

Chez la chèvre ces données sont moins documentées mais le même phénomène existe et nous avons également observé dans notre laboratoire $31 \%$ de pertes embryonnaires avant 35 jours 
Figure 1. Evolution des profils de gestation après transplantation d'embryons clonés à partir de cellules embryonnaires, somatiques fotales ou adultes. Comparaison avec les gestations issues de FIV (Heyman et al 2002).

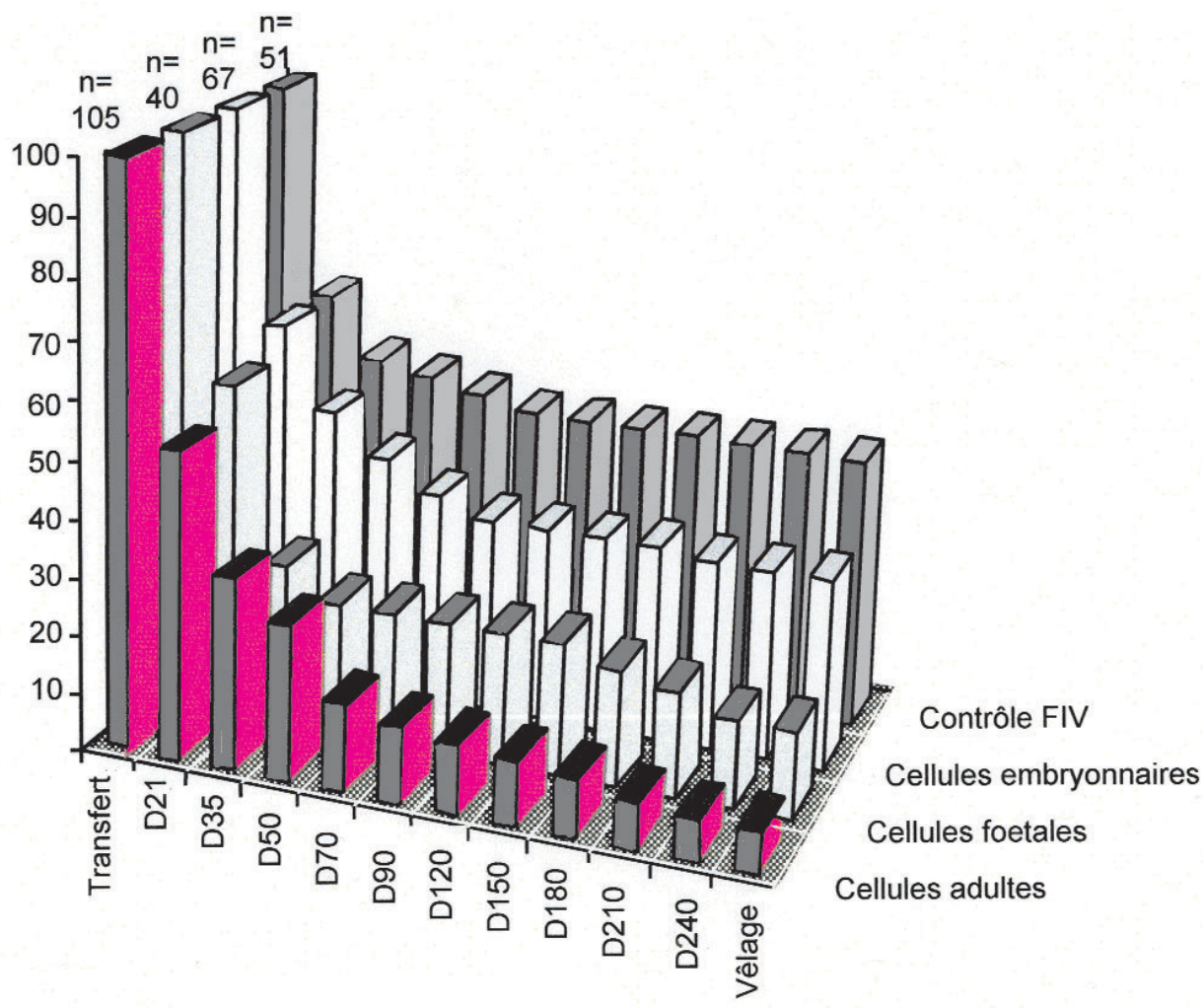

par rapport aux gestations initiées (10/32) (Chesné 2003).

\section{b) Le syndrome du gros veau}

Chez les bovins, une pathologie de la gestation apparaît fréquemment au cours du deuxième et du troisième trimestre chez les porteuses de clones somatiques. Elle est caractérisée par un développement placentaire anormal. Le nombre de placentomes est réduit mais leur poids est augmenté, un hydrallantois et/ou hydramnios apparaît et le fœtus a un poids et une taille excessifs par rapport à son âge (Large Offspring Syndrome ou LOS). Ce syndrome a été rapporté par plusieurs équipes chez le bovin (Hill et al 1999, Chavatte-Palmer et al 2002, Tsunoda et Kato 2002, Lee et al 2004) qui décrivent une hypertrophie de certains organes, des cas de stéatose hépatique, hydronéphrose, macroglossie et des vaisseaux ombilicaux souvent dilatés et oedémateux. Le syndrome LOS avait déjà été décrit chez les ovins et les bovins et n'est pas spécifique du clonage car il affecte dans une moindre mesure les gestations issues de fécondation in vitro (Walker et al 1996, Boerjan et al 2000). La teneur en sérum des milieux de culture in vitro est d'ailleurs associée à l'incidence de cette pathologie. Ces données confirment donc qu'une perturbation la croissance fœtale et placentaire ont une expression perturbée chez les fœtus clonés (Yang et al 2005). De même chez des fotus bovins clonés, des concentrations élevées de facteur de croissance IGF1 (Insulin Growth Factor) ont été mesurées en association avec une masse placentaire plus importante que dans les gestations normales (Ravelich et al 2004). Les nouveaux outils de la génomique tels que l'hybridation sur micro-reseaux d'ADNc pour détecter les expressions aberrantes de gènes spécifiques mais aussi leur dynamique d'expression, permettent maintenant d'espérer mieux comprendre les mécanismes qui conduisent à ces mortalités fœtales tardives.

\section{c) Période péri-natale et mise bas}

La fin de la gestation reste une période critique pour le développement des clones à terme chez les ruminants. Les vaches porteuses peuvent développer un hydrallantois sévère, y compris pendant le dernier mois de gestation, aboutissant à un avortement et pouvant mettre en jeu la survie de la porteuse elle-même. L'échographie répétée par voie transabdominale permet de surveiller la fin de la gestation (ChavattePalmer et al 2003) et d'intervenir pour l'interrompre si nécessaire.

très précoce du développement embryonnaire peut avoir des effets à plus long terme au cours de la gestation, voire après la naissance. Chez les bovins, les clones issus de cellules somatiques prélevées chez un animal adulte sont plus fréquemment atteints par le LOS que ceux issus de cellules d'origine embryonnaire ou fotale (Heyman et al 2002). L'origine de ces anomalies est encore très mal connue et mettrait en jeu des phénomènes épigénétiques. En effet, lors du transfert de noyaux, les profils de méthylation de l'ADN sont modifiés (Bourc'his et al 2001, Kang et al 2002, Renard 2002, Yang et al 2005). De plus, il a été montré que des gènes soumis à l'empreinte parentale (tableau 2) et impliqués dans

A terme, les vaches receveuses se préparent en général peu à la mise bas et une augmentation de la durée moyenne de la gestation est souvent constatée (non déclenchement de la parturition aux moment du terme normal, mais plutôt une dizaine de jours après) (Hill et Chavatte-Palmer 2002). De ce fait, les vêlages sont souvent induits par un traitement aux corticostéroides pour activer la maturation fotale. La mise bas a lieu par voie vaginale comme en NouvelleZélande (Wells et al 2004) ou par césarienne comme nous pratiquons à l'INRA. Dans nos conditions expérimentales, les veaux issus de clonage somatique ont un poids moyen à la nais-

Tableau 2. Exemples de gènes soumis à l'empreinte parentale qui peuvent jouer un rôle dans le développement fœtal (Young et Fairburn 2000).

\begin{tabular}{|l|l|}
\hline \multicolumn{1}{|c|}{ Gènes } & \multicolumn{1}{c|}{ Fonctions } \\
\hline U2afl & Facteur d'épissage de l'ARN \\
Peg 3 & Proteine à doigt de zinc \\
P57/Kip 2 & Régulateur du cycle cellulaire \\
Xist & Régulation du chromosome $X$ \\
Peg 1/Mest & Comportement maternel \\
Mash2 & Croissance du trophoblaste \\
Ins 2 & Régulation du développement du sac vitellin \\
Igf2, H19, Igf2r & Croissance fœtale et développement \\
\hline
\end{tabular}


Figure 2. Distribution des poids de naissance des veaux clones ou témoins (veaux femelles de race Holstein uniquement).

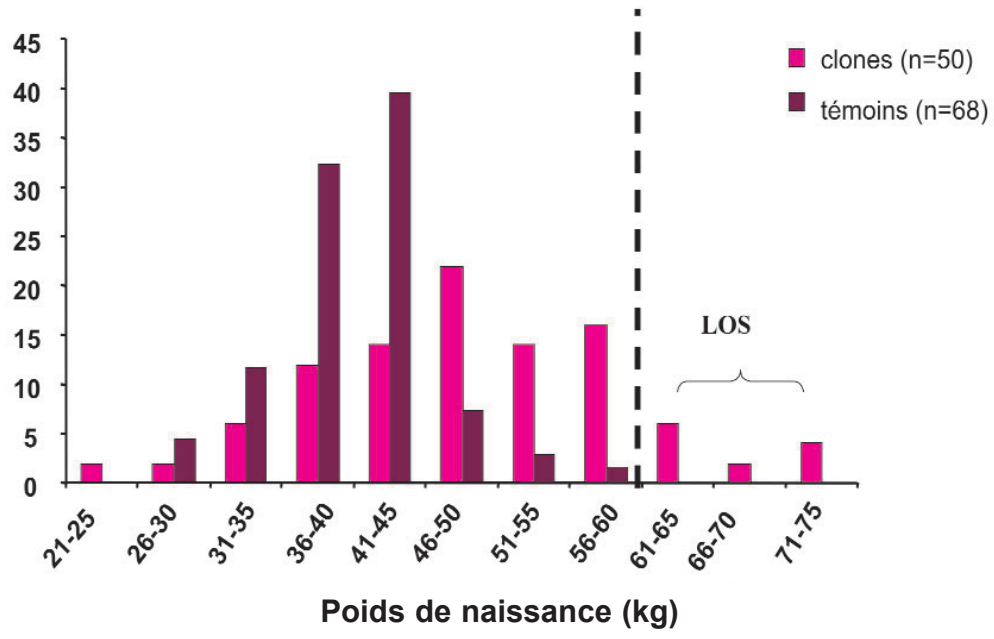

La ligne pointillée (poids moyen des veaux témoins plus 2 écarts types) marque la limite à partir de laquelle les veaux sont considérés comme atteints du « Large Offspring Syndrome » LOS.

Tableau 3. Taux de survie des clones somatiques bovins à I'INRA.

\begin{tabular}{|l|c|c|}
\hline & Nb vivants/nés & Taux de survie (\%) \\
\hline Veaux vivants à la naissance & $64 / 72$ & 89 \\
\hline Vivants après 48 h & $59 / 72$ & 82 \\
\hline Vivants après une semaine & $58 / 72$ & 81 \\
\hline Vivants à 1 mois & $54 / 72$ & 75 \\
\hline Vivants à 2 mois & $52 / 72$ & 72 \\
\hline Vivants à 6 mois & $48 / 72$ & 67 \\
\hline Adultes & $47 / 72$ & 65 \\
\hline Après réforme ou accident & $42 / 72$ & 58 \\
\hline $\begin{array}{l}\text { Après mort de pathologie d'origine } \\
\text { immunitaire }\end{array}$ & $41 / 72$ & 57 \\
\hline
\end{tabular}

Figure 3. Causes de mortalité périnatales chez les bovins clonés (Chavatte-Palmer et al 2004).

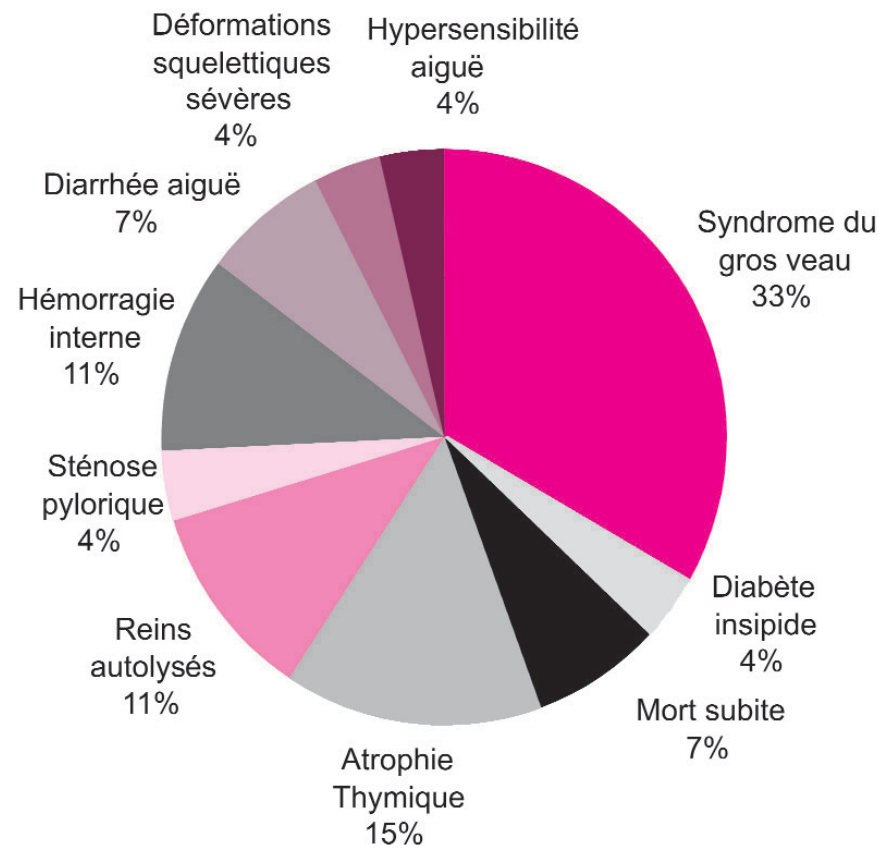

sance qui est significativement plus élevé que celui de veaux témoins contemporains issus d'IA, de même race et sexe nés au sein du même élevage $(49,27 \pm 10,98 \mathrm{~kg}$ vs $40,57 \pm 5,55 \mathrm{~kg}$, $\mathrm{P}<0,05$; Heyman et al 2004). D'autres équipes de clonage bovin ont également rapporté des poids de naissance élevés : par exemple, Pace et al (2002) rapportent un poids moyen de $51 \pm 11 \mathrm{~kg}$ chez des bovins clonés de race Holstein. La courbe de distribution des poids de naissance est également modifiée comme l'indique la figure 2 . Il est intéressant de noter que la variabilité du poids de naissance est 2 fois plus élevée chez les animaux clonés que chez les témoins. Cette distribution indique clairement l'incidence du «syndrome du gros veau» ou LOS et on considère en général qu'un veau est atteint de LOS quand son poids de naissance dépasse le poids moyen de 2 écart-types (Young et al 1998). Dans ces conditions, l'incidence du LOS est de $14 \%$ chez les veaux clonés que nous avons fait naître (7/50). Ce taux peut atteindre des proportions plus importantes selon la méthode de clonage et de culture in vitro utilisés (Kato et al 2000). Ces animaux sont en général plus fragiles et la mortalité postnatale est accrue par rapport à celle de veaux témoins issus d'IA (tableau 3) (Chavatte-Palmer et al 2004). On observe que $30 \%$ des veaux clonés meurent avant le sevrage alors que le niveau de perte n'est que de $7 \%$ chez les témoins non clonés pendant la même période. Ces chiffres sont confirmés par les données néo-zélandaises portant sur 133 naissances de veaux clonés : seulement $67 \%$ d'entre eux survivent au delà du sevrage à 3 mois (Wells et al 2004). La plupart des mortalités postnatales chez les clones interviennent au cours de la première semaine et plusieurs causes sont bien identifiées (figure 3 ) telles la détresse respiratoire, des cardiopathies du ventricule gauche ou des problèmes ombilicaux (Hill et al 1999, Gibbons et al 2002). Des mortalités postnatales des clones peuvent être liées à des insuffisances du système immunitaire dans certains cas d'hypoplasie thymique (Renard et al 1999).

Chez les petits ruminants clonés, les pertes périnatales sont également importantes mais elles sont beaucoup moins documentées que dans l'espèce bovine. Dans notre expérience de clonage caprin à partir de cellules somatiques d'origine fœtale, $36,3 \%$ des chevreaux nés n'ont pas survécu (4/11) pour des raisons de LOS ou de détresse respiratoire (Chesné 2003). Le modèle caprin est surtout utilisé pour la trans- 
génèse et dans ce cas les cellules somatiques donneuses sont soit modifiées par transfection, soit issues d'un animal déjà transgénique (Baldassare et Karatzas 2004). L'équipe Nexia Biotechnologies au Canada rapporte la naissance de 219 chevreaux clonés transgéniques parmi lesquels 150 ont survécu ce qui indique un taux de pertes postnatales de $32,5 \%$ semblable à celui observé dans l'espèce bovine.

Finalement, l'optimisation du suivi de gestation et l'apport de la surveillance échographique permettent de prédire les mortalités tardives et prévenir les souffrances des porteuses, mais aussi d'organiser la prise en charge des veaux dès les premières minutes après la naissance. Cette vigilance contribue déjà à réduire les mortalités postnatales.

\section{5 / Connaissance des animaux clonés}

La plupart des animaux clonés qui ont passé la période critique périnatale et le sevrage se développent bien et présentent une apparence physiologique normale. Les analyses récentes de Yang et al (2005) montrent que chez les clones vivants adultes, les gènes soumis à l'empreinte sont correctement exprimés, contrairement à ce que l'on trouve chez les fotus qui meurent durant la gestation. Cependant les connaissances sur ces animaux clonés sont encore limitées à travers le monde en raison du faible recul dont nous disposons pour les grands ruminants (les premiers clones somatiques bovins sont nés en 1998). Les recherches sont en cours dans plusieurs pays, pour évaluer les caractéristiques de ces animaux. Dans ce contexte, nous développons un programme de recherches de trois ans sur l'étude de la qualité des produits issus de bovins clonés avec un financement spécifique de l'INRA.

\section{a) Leur état de santé jusqu'à l'âge adulte}

Une étude clinique a été réalisée à Jouy-en-Josas sur des groupes de bovins clonés ou témoins issus d'IA, et entretenus dans les mêmes conditions au sein de l'UE INRA-Bressonvilliers. De telles études sont encore rares dans le monde, mais porteuses d'informations comparatives essentielles pour une meilleure connaissance des animaux clonés. Elle a permis de suivre les veaux jusqu'à l'âge adulte. L'analyse des différents paramètres cliniques, hématologiques ou biochi- miques montre que les veaux clonés peuvent présenter des différences par rapport aux témoins avant l'âge de deux mois mais qu'ensuite ces différences disparaissent et aucun des critères testés ne permet de les distinguer (Chavatte-Palmer et al 2004). Ainsi, par exemple, le taux d'hémoglobine est significativement plus faible chez les clones avant 60 jours bien que restant dans la limite des normes publiées dans la littérature (Chavatte-Palmer et al 2004). L'existence d'anémie subclinique montre à l'évidence que ces veaux clonés ne peuvent pas être considérés comme des individus parfaitement normaux pendant leur jeune âge.

Au delà du sevrage, l'analyse de 28 paramètres sanguins biochimiques et hématologiques chez 9 clones et 9 témoins jusqu'à l'âge de 2 ans n'a révélé aucune différence entre animaux qui puisse être un indicateur de perturbations hépatiques ou rénales (Wells et al 2004). Notre étude clinique en cours ne montre pas non plus de différence dans l'évaluation de la physiologie des clones à l'âge de 3 ans (ChavattePalmer et al 2004). Il est encore prématuré de conclure sur la longévité des animaux clonés, surtout chez les bovins. Il n'y a pas de démonstration d'un vieillissement prématuré chez les clones. Les souris clonées peuvent avoir une longévité comparable à celle de souris témoins. Ainsi plusieurs souris clonées obtenues au laboratoire ont vécu plus de deux années dont une jusqu'à 902 jours, un âge respectable chez cette espèce (Beaujean et al 2005). Ces données confirment celles rapportées par un groupe japonais (Ogura et al 2002).

Sur la base de mesures de longueur de télomères, il a été dit que la brebis Dolly comportait des cellules qui correspondaient à celles d'une brebis plus vieille de 6 ans (l'âge de la brebis donneuse de cellule). Ce résultat n'a pas été confirmé chez d'autres espèces et le critère de la longueur des télomères, sujette à de grandes variations d'un

Tableau 4. Vitesse de croissance (GMQ) des veaux clonés et de leurs témoins contemporains entre la naissance et l'âge de 12 ou 15 mois.

\begin{tabular}{|l|c|c|}
\hline \multicolumn{1}{|c|}{ Groupes } & Nombre d'animaux & $\begin{array}{c}\text { GMQ } \\
\text { Kg/jour } \pm \text { écart-type }\end{array}$ \\
\hline Clone A (0-12 mois) & $\mathrm{N}=8$ & $0,701 \pm 0,064$ \\
Témoins contemporains (0-12 mois) & $\mathrm{N}=10$ & $0,804 \pm 0,113$ \\
\hline Clone B (0-15 mois) & $\mathrm{N}=6$ & $0,782 \pm 0,041$ \\
Clone C (0-15 mois) & $\mathrm{N}=9$ & $0,711 \pm 0,061$ \\
Témoins contemporains (0-15 mois) & $\mathrm{N}=10$ & $0,766 \pm 0,089$ \\
\hline
\end{tabular}

individu à l'autre, doit être interprété avec beaucoup de précaution. Le cytoplasme de l'œuf possède une activité télomérase, qui permet au noyau somatique transplanté de retrouver une longueur de télomères similaire à celle rencontrée dans des individus non clonés de même âge comme cela a été montré chez la souris et le bovin (Miyashita et al 2002, Miyashita et al 2003). Néanmoins, il est nécessaire de recourir à une enquête internationale pour évaluer la survie à long terme des bovins clonés sur un effectif suffisant. Il a été mentionné (Wells et al 2004) des mortalités de bovins clonés à l'âge adulte de l'ordre de $8 \%$, pouvant laisser suspecter une réponse immunitaire réduite en cas d'infection, mais les premières études de caractérisation lymphocytaires chez les clones se sont révélées normales (Lanza et al 2001). Parmi nos bovins issus de clonage somatique, les vaches les plus âgées que nous suivons actuellement ont entre 6 et 7 ans. En Ecosse, la brebis Megan née en 1995 est toujours en vie, elle a été clonée à partir de cellules embryonnaires cultivées et modifiées génétiquement, et atteint ses 10 ans (Wilmut communication personnelle).

b) Des performances zootechniques qui ne sont pas différentes de celles d'animaux non clonés issus d'IA

La croissance des veaux issus de clonage somatique a été comparée à celle de témoins élevés dans les mêmes conditions. Les vitesses de croissance jusqu'à l'âge de 15 mois, mesurées chez 3 familles de clones de différentes origines génétiques sont normales et comparables aux témoins (tableau 4). Pour chaque clone au sein d'une même famille, le Gain Moyen Quotidien (GMQ) n'est pas affecté par le poids de naissance. Ceci semble indiquer que l'environnement prénatal qui est impliqué dans le surpoids à la naissance n'a plus d'influence sur la croissance pondérale ultérieure. Les mesures d'indice de consommation des veaux clonés sont comparables à celles de veaux témoins issus d'IA avec la même origi- 
ne paternelle. Les concentrations plasmatiques en hormone de croissance (GH) ne sont pas différentes entre 5 et 11 mois chez les animaux clonés ou témoins (Govoni et al 2002).

La production laitière des vaches clonées a été étudiée sur le plan quantitatif (Norman et Walsh 2004) et qualitatif. La composition du lait de vaches clonées fait l'objet de beaucoup d'attention dans le contexte actuel d'un moratoire INRA interdisant l'introduction des produits issus de clones dans la chaîne alimentaire humaine. Une étude (Walsh et al 2003) portant sur l'analyse complète du lait de 15 vaches clonées issues de 5 génotypes et trois races différentes n'a pas permis de mettre en évidence une différence dans la composition du lait de clones ou de témoins que ce soit pour la composition chimique, les acides gras ou les profils de protéines. La valeur nutritionnelle du lait issu de bovin cloné fait l'objet de comparaisons sur le modèle rat (Tomé et al 2004). L'ingestion d'un régime à base de lait ou de viande de clones n'induit chez le rat aucune différence de prise alimentaire, de prise de poids ni de composition corporelle, par rapport au lot témoin soumis à un régime de même composition mais élaboré à partir de produits d'animaux non clonés (données non publiées, Fromentin et $a l)$. De plus, aucune allergénicité des produits issus de clones n'a pu être mise en évidence, à ce jour, chez les rats ainsi nourris (données non publiées, Dubarry et al). La composition de la viande de bovin cloné a également été analysée sur une centaine de paramètres (Berthelot et al 2004, Tian et al 2005) et aucune différence significative n'a pu être mise en évidence par rapport à la viande d'animaux témoins non clonés. Toutefois ces études ne portent encore que sur un nombre limité d'animaux.

\section{c) Leur aptitude à la reproduction} sexuée

De nombreuses publications ont montré que des animaux clonés mâles ou femelles de différentes espèces sont féconds (Wells 2003, Gauthier et al 2001, Lanza et al 2001). Les génisses clonées ont une fertilité normale après insémination artificielle (Wells et al 2004). Elles sont capables de vêler spontanément à terme et sans aide contrairement aux porteuses de foetus clonés. Les descendants de génisses clonées ont un poids de naissance normal et une survie postnatale correcte puisque $85 \%$ d'entre eux survivent jusqu'à l'âge adulte selon les données de
Ag Research en Nouvelle Zélande. A l'INRA, nous avons inséminé un nombre limité de génisses clonées $(\mathrm{n}=10)$ toutes sont devenues gestantes après 1 à 4 IA, ont vêlé normalement et produit 10 veaux, tous vivants et ne présentant aucune des anomalies phénotypiques caractéristiques du LOS. D'autre part, 3 génisses clonées ont été saillies naturellement par un taureau cloné et ont donné naissance à 3 veaux qui se développent normalement. Ceci confirme chez le bovin que des animaux clonés peuvent se reproduire entre eux comme cela avait été démontré chez la souris (Shimozawa et al 2002, Tamashiro et al 2002). De même, chez la brebis Wells (2003) rapporte la naissance de 3 agneaux en croisant deux femelles clonées avec un bélier cloné d'une autre race.

Les mâles clonés ont une libido normale et les collectes de sperme de taureaux clonés réalisées aux USA et au Canada indiquent que la production de semence est conforme aux paramètres attendus. La fertilité est actuellement évaluée à la fois in vivo et in vitro (Bousquet et Blondin 2004). En France, une expérimentation est en cours dans le cadre d'une convention entre l'INRA et l'UNCEIA pour évaluer sur le plan quantitatif et qualitatif, la production de semence d'un taureau cloné de race charolaise en comparaison avec celle du taureau original. Par ailleurs, la comparaison de l'analyse morphologique de la semence congelée d'un taureau avec celle de ses 3 clones n'a pas permis de déceler une éventuelle modification du taux d'anomalies due au clonage (Heyman et al 2004). Enfin, une étude japonaise récente (Shiga et al 2005) montre que la semence congelée de deux taureaux clonés, utilisée en IA, a la même fertilité que celle du taureau donneur de noyaux et que la descendance de ces taureaux clonés a un poids de naissance conforme et une croissance normale.

Les différentes observations réalisées à ce jour sur la descendance des clones bovins ne révèlent aucune des anomalies phénotypiques ou cliniques associées par exemple au large offspring syndrome. Ainsi, les perturbations observées chez les clones eux-mêmes seraient bien d'origine épigénétique et n'ont pas vocation à être transmises à la descendance. La démonstration la plus convaincante de cette non transmission a été réalisée chez la souris en croisant des souris obèses obtenues par clonage à partir d'une lignée spécifique de cellules souches ES associée à l'hypertro- phie placentaire et foetale (Shimozawa et al 2002). Tous les descendants de ces croisements sont normaux et ceci prouve que les anomalies épigénétiques dans l'expression de certains gènes des clones sont corrigées au cours de la gamétogenèse.

\section{6 / Utilisation des clones comme modèles}

Les données présentées précédemment montrent que les clones ont en général un développement fœtal perturbé, avec un retard de croissance en période péri-implantatoire auquel succède une période de croissance fœtale exagérée. Des études épidémiologiques conduites chez l'homme et des données expérimentales chez l'animal montrent que des pathologies prévalentes dans certaines populations humaines, comme l'hypertension ou la résistance à l'insuline, trouvent leur origine pour partie dans des dérégulations de la nutrition du fœtus à des périodes critiques de son développement (Barker et al 2002), y compris pendant la période périconceptionnelle (Kwong et al 2000, Fleming et al 2004). Des dérégulations d'origine épigénétique sont proposées comme l'un des facteurs étiologiques pour ces effets.

Afin d'étudier les mécanismes impliqués dans ces phénomènes, des modèles animaux sont développés. Le modèle du clone de ruminant prend naturellement sa place dans cette problématique. En effet, les clones bovins ou caprins, qui présentent un fort taux d'anomalies du placenta en cours de gestation, permettent d'étudier les effets des perturbations de la vie fotale et de s'affranchir des effets dus à la variabilité génétique.

\section{7 / Evaluation des risques associés au clonage}

Les récents progrès du clonage font que cette biotechnologie s'approche de la frontière entre la phase de recherche et les possibilités d'applications commerciales. Ceci suscite une prise de conscience à la fois sur les risques potentiels, la perception du public et la nécessité d'encadrer l'utilisation des techniques nouvelles. Actuellement, il n'y a pas encore de réglementation spécifique du clonage au niveau Européen. En France, le clonage est encadré par un moratoire INRA du 6 juillet 1999 qui interdit formellement la mise sur le marché de tout produit issus de clones et implique l'élimination du lait, la destruction des animaux clonés et même 
de leurs descendants en fin d'expérimentation. Cependant des regroupements d'experts européens (Institute of Prospective Technological Studies, IPTS) se mettent en place pour organiser une politique commune de recherches sur l'évaluation de risques associés à la technologie du clonage et à ses applications. L'approche pluridisciplinaire engagée à l'INRA depuis trois ans dans le cadre du programme «Expertise de la Qualité et de la sécurité des produits issus de bovins clonés» s'inscrit tout à fait dans cette perspective. Les résultats de ces recherches sont très attendus par les organismes tels que la FDA américaine (Food and Drug Administration) ou l'AFSSA en France (Agence Française de Sécurité Sanitaire des Aliments). Ils contribueront à l'élaboration de recommandations sur l'utilisation des produits de clones dans la chaîne alimentaire. Sur le plan sanitaire, l'Office International des Epizooties (OIE) vient d'adopter une résolution (26 mai 2005) pour soutenir la mise en place de normes harmonisées visant à encadrer les produits de santé animale issus des biotechnologies, ceci en collaboration avec d'autres organisations internationales comme la FAO (Food Agriculture Organisation), l'OMS (Organisation Mondiale de la Santé ) et l'IETS (International Embryo Transfer Society).

En plus des études sur la santé des animaux clonés et de leurs performances zootechniques décrites plus haut, les risques étudiés concernent :

- les risques sanitaires liés aux produits de clones

Nous avons entrepris une étude sur le risque sanitaire lié aux séquences rétrovirales endogènes (BERV) chez les bovins clonés, dans l'éventualité d'une réactivation de certaines séquences au cours de la reprogrammation du noyau. Les premiers résultats montrent de façon convaincante que ces séquences sont bien présentes dans le génome des bovins témoins ou clonés mais qu'elles ne sont pas transcrites et que le clonage ne modifie pas le nombre de copies des BERV dans le génome des clones par rapport aux témoins (données non publiées, Martignat et al).

- les risques génétiques associés à la technique

Dans les cellules somatiques, outre les altérations épigénétiques telles que la méthylation, l'acétylation ou la longueur des télomères qui sont traitées dans d'autres parties de cet article, des mutations apparaissent spontanément dans l'ADN lors de la multiplication de ces cellules (Drake et al 1998). Le recours à des cellules donneuses de noyaux cultivées in vitro sur de longues périodes ainsi que les manipulations des embryons eux-mêmes augmentent le risque d'obtention d'animaux clonés porteurs de mutations. Dans le cas d'application du clonage à la production de géniteurs d'intérêt ou d'animaux génétiquement identiques, il est nécessaire d'évaluer dans quelle mesure le génome de clones issus de cellules somatiques pourrait être différent de celui du génotype d'origine. Les analyses basées sur les seuls marqueurs de séquences microsatellites sont très insuffisantes pour affirmer que des réarrangements minimes ou des mutations ponctuelles ne sont pas présents dans les cellules et gamètes d'animaux clonés. Des méthodes plus sensibles (jusqu'à 4 kb de différence) sont actuellement mises en œuvre chez le bovin pour comparer de façon réaliste des fractions importantes du génome entre individus d'un même clone (De Montera et al 2004).

De plus, contrairement à la fécondation qui conduit à une destruction des mitochondries du sperme par le cytoplasme ovocytaire, l'ADN mitochondrial dérivé des cellules donneuses peut être conservé dans des embryons, fotus et nouveau-nés issus de transfert de noyau somatique (Takeda et al 2003). Même si cette hétéroplasmie est généralement limitée ou progressivement perdue lors des générations suivantes, la susceptibilité de l'ADN mitochondrial à subir des mutations ou des recombinaisons pourrait conduire à la transmission d'ADN mitochondrial muté chez les clones et leurs descendants (Smith et Murphy 2004, Hiendleder et al 2005). Il convient là aussi d'évaluer ce risque.

\section{2 / Les barrières biolo- giques a maîtriser}

\section{1 / Les cellules donneuses de noyaux}

\section{a) Quel type de cellules ?}

Les noyaux de cellules somatiques provenant de différents tissus ont démontré leur aptitude à conduire à un développement à terme après transfert de ces noyaux dans des ovocytes énuclées. Toutefois l'efficacité peut varier considérablement selon la source de noyaux pour des raisons encore peu comprises. Les fibroblastes issus de biopsies de peau d'animal adulte sont largement utilisés du fait de la facilité de prélèvement et de maintien en culture in vitro. Si la grande plasticité de ce type cellulaire peut expliquer leur relative efficacité dans le clonage, il faut signaler que la plupart des tissus, qu'ils soient fœtaux ou adultes, contiennent des cellules qui ont permis de produire des clones (Kato et al 2000). Une limite persiste avec la culture in vitro des cellules somatiques qui est pourtant une étape indispensable si l'on veut combiner le clonage avec la modification génétique ciblée de ces cellules. Dans ces conditions, le recours aux cellules fœtales est préférable (Reggio et al 2002, Kuroiwa et al 2004). Ainsi, en repartant de cellules prélevées sur des fœus eux-mêmes clonés, on peut modifier progressivement le génome des cellules donneuses à chaque nouvelle mise en culture. L'invalidation totale de deux gènes par knock-out a pu être réalisée après quatre étapes de clonage-remise en culture chez le bovin (Kuroiwa et al 2004). Mais, le potentiel de développement des embryons reconstitués s'amenuise avec le nombre de recyclages ainsi produits (Robl J. communication personnelle). Par ailleurs, Zakhartchenko et al (1999) ont montré que chez la vache, une lignée de cellules établie à partir de glande mammaire avait des noyaux totalement incapables de conduire un développement normal alors que ces mêmes noyaux prélevés dans des cultures primaires pouvaient, après transfert dans des ovocytes, aboutir à des naissances. On peut donc penser qu'au cours de la culture in vitro, les cellules de mammifères accumulent des mutations, des pertes d'empreinte ou d'autres altérations épigénétiques, indécelables par les techniques standard de caryotypage (Kasinathan et al 2001).

\section{b) Origine génétique des animaux} donneurs de cellules

Outre l'effet culture, un effet animal d'origine a également été observé. Chez le bovin, des expériences à partir de cellules fotales traitées dans des conditions de culture variables ont montré que le facteur majeur de variation était celui du fœtus d'origine (Powell et al 2004). On peut dès lors se demander si le fonds génétique n'est pas aussi un facteur à prendre en compte. Dans notre laboratoire, nous avons réalisé le transfert de noyaux à partir de fibroblastes issus de biopsie de peau de bovins adultes de différentes origines et comparé le développement in vitro des embryons reconstitués (tableau 5). Le pourcentage de blastocystes obtenus après 7 jours de culture des embryons 
Tableau 5. Potentiel de développement des embryons bovins clonés selon l'origine génétique de l'animal donneur (source de fibroblastes de peau).

\begin{tabular}{|c|c|c|c|c|c|c|}
\hline \multirow[b]{2}{*}{$\begin{array}{l}\text { Origine } \\
\text { donneur }\end{array}$} & \multirow[b]{2}{*}{ Sexe } & \multicolumn{2}{|c|}{ Développement in vitro } & \multicolumn{3}{|c|}{ Développement in vivo } \\
\hline & & $\begin{array}{l}\text { Blastocystes/ } \\
\text { reconstitués }\end{array}$ & $\begin{array}{c}\text { Taux } \\
\text { blastocystes } \\
\%\end{array}$ & Gestations* & $\begin{array}{l}\text { Veaux nés/ } \\
\text { Embryons } \\
\text { transplantés }\end{array}$ & $\begin{array}{c}\text { Rendement }^{* *} \\
\%\end{array}$ \\
\hline $\mathrm{N}^{\circ} 10$ & Male & $23 / 363$ & 6,3 & $5 / 18$ & $3 / 23$ & 13,0 \\
\hline $\mathrm{N}^{\circ} 03$ & Femelle & $19 / 180$ & 12,8 & $2 / 12$ & $1 / 19$ & 5,3 \\
\hline $\mathrm{N}^{\circ} 86$ & Male & $47 / 215$ & 21,9 & $8 / 29$ & $5 / 40$ & 12,5 \\
\hline $\mathrm{N}^{\circ} 11$ & Femelle & $39 / 217$ & 18,0 & $13 / 20$ & $2 / 32$ & 6,2 \\
\hline $\mathrm{N}^{\circ} 04$ & Femelle & $17 / 111$ & 15,3 & $4 / 8$ & $3 / 14$ & 21,4 \\
\hline $\mathrm{N}^{\circ} 29$ & Femelle & $127 / 352$ & 36,1 & $8 / 85$ & $2 / 85$ & 3,3 \\
\hline $\mathrm{N}^{\circ} 38$ & Femelle & $138 / 322$ & 42,9 & $27 / 60$ & $15 / 60$ & 25,0 \\
\hline
\end{tabular}

* $\mathrm{Nb}$ de gestations confirmées à 2 mois/nb de receveuses transplantées.

** rendement $=$ nb veaux nés par rapport au nb d'embryons transplantés.

(Données INRA, Heyman et al 2002, Vignon et al 2003).

reconstitués peut varier de $6 \%$ à près de $45 \%$ selon les lignées de fibroblastes. De plus, le développement à terme de ces blastocystes clonés peut varier de $3 \%$ à $25 \%$ selon l'origine de l'animal donneur utilisé comme source de noyaux. Néanmoins, pour un même animal donneur, les taux de développement in vitro et in vivo des embryons reconstitués ne sont pas corrélés. L'obtention de blastocystes après transfert nucléaire n'est donc pas un bon indicateur du potentiel de développement à terme des embryons clonés.

c) Age des animaux donneurs de cellules

Il n'y a pas, a priori, de relation directe entre l'âge du donneur et le potentiel de développement des embryons clonés, des taureaux âgés de 17 et même 21 ans ont pu être clonés avec succès (Hill et al 2000, Kubota et al 2000). Nous avons confirmé cette possibilité de cloner à partir de donneurs âgés, en particulier à partir d'une vieille vache rustique mais stérile de 16 ans sur laquelle un prélèvement de peau a été réalisé juste avant sa mort. Son clone s'est développé normalement et a déjà produit 2 descendants après IA.

Ce résultat sur l'absence d'effet de l'âge du donneur était inattendu car les noyaux des cellules somatiques ont une capacité de division limitée : ils perdent progressivement l'aptitude à exprimer le complexe ribo-nucléo-protéique de la télomérase. La restauration de la longueur des télomères chez les animaux clonés dépendrait du type de cellules donneuses utilisées. Ainsi selon Miyashita et al (2002) les bovins clonés ont des télomères normaux quand ils sont obtenus à partir de cellules musculaires ou fibroblastes, et ceci même quand l'animal donneur est âgé.

\section{2 / Le cytoplasme receveur}

Le transfert de noyaux implique de pouvoir disposer d'un grand nombre d'ovocytes receveurs au stade métaphase II. Chez les ruminants et en particulier les bovins, les méthodes de maturation in vitro (MIV) sont efficaces et permettent de produire ces ovocytes à partir d'ovaires collectés à l'abattoir ou par Ovum pick up sur l'animal vivant. Les ovocytes bloqués au stade de la vésicule germinative sont aspirés dans les follicules à antrum puis cultivés in vitro en présence d'hormones gonadotropes ou de facteurs de croissance (Lonergan et al 1996), pour la reprise de la méiose jusqu'au stade métaphase II. Le milieu le plus généralement utilisé pour la maturation in vitro (TCM 199) est un milieu tamponné au bicarbonate, contenant des sources de carbone et d'énergie (glucose, glutamine) ainsi que des acides aminés et vitamines. Il est supplémenté en protéines telles que l'albumine bovine sérique (BSA) pour empêcher l'adhésion des complexes cumulus-ovocytes à la surface des boites de cultures, et de FSH/LH qui stimulent l'expansion du cumulus. Cette étape est obtenue en $24 \mathrm{~h}$ pour l'ovocyte de bovin. L'origine des ovocytes influence leur compétence cytoplasmique comme cela avait été démontré par fécondation in vitro, ainsi les cytoplasmes ovocytaires issu de génisses prépubères ou de vaches adultes ont des aptitudes au développement significativement différentes après transfert de noyaux (Mermillod et al 1998), les meilleurs taux de développement étant obtenus à partir d'ovocytes de vaches adultes. De plus, le développement in vitro des embryons est influencé par la vache donneuse d'ovocytes (Tamassia et al 2003).

Les ovocytes obtenus par MIV sont énucléés pour les débarrasser de leur propre information génétique. Pour cela les chromosomes de la plaque métaphasique ainsi que le premier globule polaire sont extraits de l'ovocyte, généralement par micromanipulation. Cette étape est encore limitante dans la technique de transfert de noyau et plusieurs procédés alternatifs sont à l'étude pour améliorer l'efficacité d'énucléation tout en minimisant les effets néfastes liés à la perte de cytoplasme ou à l'altération mécanique de l'ovocyte (Li et al 2004).

\section{3 / Reconstitution/activation}

\section{a/ Importance des relations nucléo- cytoplasmiques}

Dès son introduction dans le cytoplasme ovocytaire, le noyau de la cellule somatique va subir des remaniements importants qui seront décisifs pour sa «reprogrammation» ou son retour à l'état «totipotent» (Vignon et al 2002). La cinétique de ces modifications morphologiques dépend de la position du noyau dans son propre cycle cellulaire et de celle du cytoplas- 
me receveur. La coordination des cycles respectifs du noyau donneur et de l'ovocyte receveur est importante pour maintenir un génome diploïde et fonctionnel dans l'embryon reconstitué. Le facteur ovocytaire MPF (Mphase Promoting Factor) a une activité élevée dans les ovocytes jeunes au stade métaphase II et chute au cours de l'activation et de la progression vers l'interphase. Les noyaux transplantés dans des cytoplasmes à forte activité MPF vont subir une rupture de leur membrane nucléaire puis une condensation de leur chromatine tandis que ceux transplantés dans des ovocytes âgés ou «préactivés», à faible activité MPF, vont au contraire connaître un gonflement et une décondensation de leur chromatine (Adenot et al 1997). Ces transformations subies par le noyau sont associées à des échanges de protéines entre le noyau donneur et le cytoplasme receveur et à une diminution marquée de l'activité transcriptionnelle de ce noyau somatique. Parmi les protéines échangées, les histones jouent un rôle prépondérant dans la conformation de la chromatine. Des études sur la dynamique des histones dans les embryons issus de transfert de noyau révèlent que l'échange des histones $\mathrm{H} 1$ somatiques de la chromatine du noyau donneur est assuré d'autant plus rapidement que l'enveloppe du noyau est partiellement ou totalement résorbée après le transfert (Adenot et al 2000, Bordignon et al 2001). Des stratégies peuvent donc être définies pour optimiser la reconstitution d'un zygote à partir d'un noyau somatique et mieux maîtriser le contrôle exercé par l'environnement cytoplasmique sur l'activité du noyau (Renard et Vignon 2001).

Dans ce contrôle que l'on qualifie d' "épigénétique», les modifications structurales de la chromatine telles que la méthylation de l'ADN et des histones jouent un rôle important (Beaujean et al 2005). Les relations entre le remodelage de la chromatine après transfert de noyau et la méthylation des gènes sont encore mal connues et leur compréhension pourrait permettre de réduire les anomalies de développement placentaires et fœtales fréquemment observées chez les clones.

Enfin, l'activation de l'œuf reconstitué est également une étape cruciale et le contrôle des évènements (en particulier les flux de calcium) qui participent à l'activation et aux premiers remaniements du noyau étranger pourrait permettre d'en limiter les variations. Une meilleure maîtrise des paramètres d'activation peut être obtenue en «pilotant» les oscillations calciques du début du développement grâce à des techniques de microfluidique permettant des variations rapides de la composition minérale de l'environnement de culture (Ozil et al 2005).

\section{b) La culture in vitro des embryons} reconstitués

Des progrès importants ont été réalisés dans les méthodes de culture in vitro des embryons de ruminants. Ces progrès sont directement issus des recherches conduites pour améliorer le rendement de la FIV, notamment chez les bovins et les techniques de culture in vitro des zygotes issus de FIV ont été appliquées aux embryons reconstitués par transfert de noyaux. Après fusion et activation, les embryons reconstitués sont généralement cultivés sous atmosphère contrôlée en $\mathrm{CO} 2$ dans des milieux définis (SOF, CR1aa,) ou séquentiels ou bien encore en coculture avec des cellules Véro qui secrètent les facteurs de croissance nécessaires dans le milieu. Les taux de blastocystes obtenus varient selon la lignée de cellules donneuses mais peuvent atteindre $50 \%$ c'est-à-dire des taux de développement in vitro tout à fait comparable à celui des embryons issus de FIV. Les blastocystes clonés ont une morphologie apparemment normale si l'on en juge par le nombre de noyaux et leur répartition dans le bouton embryonnaire et le trophoblaste (nos observations). Cependant cette morphologie peut masquer des différences fonctionnelles qui se traduiront par des mortalités embryonnaires accrues après transplantation dans des porteuses. Il est démontré que les techniques de culture in vitro et de transfert de noyaux utilisées pour générer ces blastocystes, sont associées à des dérégulations de certains gènes critiques pour le développement ultérieur (Wrenzycki et al 2005). L'analyse des profils d'expression des gènes dans l'embryon cloné par hybridation sur micro réseau d'ADNc en comparaison avec l'embryon obtenu in vivo après IA, devrait permettre de mieux comprendre les causes de ces anomalies du développement et d'optimiser en conséquence les méthodes de production d'embryons in vitro. Une telle démarche est en cours au laboratoire, et sera étendue à l'embryon de lapin comme modèle.

\section{3 / Applications envisagées}

\section{1 / Innovations thérapeutiques et biomédicales}

Une utilisation du clonage somatique associée à la transgénèse permet d'obtenir avec une meilleure efficacité des animaux génétiquement modifiés pour des applications de type biomédicales telles que la production de protéines recombinantes humaines, ou l'obtention de modèles animaux. Cette approche est surtout développée chez les petits ruminants.

\section{a) Exemple du mouton}

Le mouton est l'un des modèles utilisés pour produire des molécules pharmaceutiques. Ainsi des brebis clonées à partir de fibroblastes transfectés produisent un anticoagulant, le facteur IX humain (Schnieke et al 1997). Plus récemment, la transgénèse ciblée devient accessible puisque malgré une fréquence de recombinaison homologue très faible obtenue sur des fibroblastes fœtaux ovin, il a été démontré que cette transgénèse ciblée sur le locus procollagène (Col1A1) permettait d'obtenir des jeunes après clonage (McCreath et al 2000). Le mouton, en raison de sa taille, peut être un candidat intéressant pour générer des modèles d'étude de la fibrose cystique humaine en ciblant une mutation sur le gène en question.

Un transgène commercialement important, l'alpha-1 antitrypsine a pu être inséré dans des fibroblastes ensuite utilisés en transfert nucléaire pour donner naissance à des agnelles transgéniques. Il faut noter cependant qu'une mortalité post-natale très élevée a été observée dans les expériences utilisant des cellules modifiées (McCreath et al 2000, Denning et al 2001). Ceci suggère que certaines combinaisons de culture à long terme et modifications des cellules ne sont pas compatibles avec leur utilisation pour le clonage par transfert de noyau.

\section{b) Exemple de la chèvre}

Aux Etats-Unis, Behboodi et al (2002) rapportent la naissance de 22 chèvres clonées à partir de cellules fœtales transfectées sans incidence particulière du LOS. L'espèce caprine est intéressante pour l'obtention de molécules pharmaceutiques à usage humain telles que protéines recombinantes ou anticorps dans le lait (Reggio et al 2002). 
Le clonage est utilisé non seulement pour obtenir des animaux transgéniques à partir de cultures de cellules transfectées mais également à partir de biopsies de chèvres elles-mêmes transgéniques et ainsi multiplier les fondateurs d'un troupeau transgénique dans le cas de la production de molécules pharmaceutiques (Keefer et al 2002).

La chèvre clonée et transgénique est également un modèle intéressant pour aborder des problèmes fondamentaux qui ont des répercussions en médecine humaine. Par exemple, le rôle du gène FoxL2 dans la différenciation sexuelle est en cours d'étude à l'aide de chèvres «sans cornes» porteuses de la mutation PIS (Polled Intersex Syndrome). Cette délétion (Pailhoux et al 2001) est responsable de la régulation de 3 gènes et nous utilisons la transgénèse pour modifier l'expression de l'un ou l'autre de ces gènes dans des cellules fœtales en culture. Le clonage à partir de ces cellules est actuellement utilisé dans notre laboratoire pour générer des fœtus dont l'étude phénotypique et expressionnelle permettra de préciser le rôle respectif de ces 3 gènes.

\section{2 / Innovations agronomiques pour la gestion génétique}

a) Le clonage : un nouvel outil pour la sélection bovine

L'identification des gènes d'intérêt agronomique et la caractérisation de leur variabilité dans les populations animales sont des objectifs majeurs en élevage. La recherche de ces gènes repose aujourd'hui largement sur des stratégies de sélection qui, à partir d'une masse d'informations recueillies sur le phénotype et la parenté des animaux, permettent de prédire la valeur génétique des reproducteurs à l'aide d'outils statistiques appropriés. La stratégie utilise des modèles de génétique quantitative où le phénotype d'un animal est considéré comme une fonction des interactions entre la somme de l'expression des gènes et les effets de facteurs environnementaux.

C'est dans ce contexte que les applications potentielles du clonage avaient été présentées dans un précédent numéro de la revue INRA Productions Animales (Colleau et al 1998). Nous montrions que pour la sélection bovine, le clonage pourrait en théorie présenter les avantages suivants :

- connaître avec plus de précision, plus rapidement et à moindre coût la valeur génétique du reproducteur. Par exemple en race laitière, la précision avec laquelle pourrait être estimée la valeur génétique d'un clone de 5 femelles serait la même que celle estimée par les lactations de 25 filles d'un même taureau, mais en utilisant 5 fois moins d'animaux,

- multiplier les meilleurs animaux pour augmenter la diffusion du progrès génétique. Cette application doit bien entendu être encadrée pour empêcher une utilisation excessive de certains génotypes,

- offrir une garantie en cas d'accident d'un jeune reproducteur mâle mis au testage,

- multiplier des taureaux à index élevé et les introduire pour la monte naturelle dans des systèmes extensifs de production de viande comme le propose un groupe australien (Wells communication personnelle). Une telle approche permettrait de compenser la difficulté de pénétration de l'IA en élevage viande.

Compte tenu du coût actuel de production d'un reproducteur cloné, 15000 à $25000 \$$ selon les estimations de la compagnie américaine Trans Ova Genetics (Faber et al 2004), mais aussi de la perception sociétale négative du clonage, l'utilisation des clones en sélection n'est pas encore d'actualité ! Toutefois, nous avons vu que l'efficacité de la technique progresse et qu'il est possible maintenant d'obtenir régulièrement des clones bovins adultes normaux et fertiles. En outre la perception très négative du clonage pourrait elle aussi évoluer si le taux de mortalités fœtales tardives diminuait et surtout si des intérêts majeurs des applications agronomiques de la technique pouvaient être montrés : par exemple, une garantie sanitaire des produits bovins pourrait être apportée par l'obtention d'animaux knock out homozygotes comme cela a été réalisé pour le gène de la protéine prion (Kuroiwa et al 2004).

D'ores et déjà, de nouveaux intérêts du clonage se font jour pour la sélection animale. Celle-ci tire aujourd'hui avantage de nouvelles méthodes moléculaires qui permettent de repérer, à partir de marqueurs appropriés (sélection assistée par marqueurs ou SAM), les régions chromosomiques associées aux gènes d'intérêt (approche QTL) voire les gènes eux-mêmes. Ainsi, le recours à la multiplication par clonage d'embryons porteurs des mêmes gènes nucléaires, permettrait de réaliser la SAM sur un ou plusieurs embryons d'un même clone afin de ne transplanter dans les vaches receveuses que les embryons porteurs des régions d'intérêt. Toutefois, les données récentes de la recherche sur les génomes montrent que le fonctionnement des gènes est plus complexe que la somme d'une activité de gènes en interaction avec l'environnement. Une «troisième composante» de nature épigénétique (Gartner et Baunack 1981) doit être prise en compte dans les modèles théoriques de la génétique quantitative, ne serait ce que pour garantir la durabilité de la sélection. Les clones pourraient permettre d'introduire cette troisième composante de façon opérationnelle dans les schémas de sélection de la façon suivante :

- les régulations épigénétiques sont celles qui affectent l'expression des gènes de manière héritable au cours des divisions cellulaires (en mitose, voire en méiose) mais sans impliquer de modifications des séquences nucléotidiques de l'ADN. La méthylation de l'ADN est la modification épigénétique la plus étudiée à ce jour. Elle est importante pour le fonctionnement de gènes impliqués par exemple dans la croissance fotale et postnatale chez le mouton (Georges et al 2003) et le porc (Quintanilla et al 2002) ou dans le comportement maternel (Szeto et al 2004). Elle est aussi responsable des dysfonctionnements des gènes à empreinte parentale qui s'expriment différemment selon que le même allèle provient du père ou de la mère. Il est devenu important d'introduire ces nouvelles connaissances dans les études sur la variabilité phénotypique des caractères,

- le remodelage du noyau, étroitement associé au clonage surtout au début du développement de l'embryon, est source de modifications épigénétiques importantes qui expliquent en partie les échecs nombreux du clonage. Les clones se révèlent alors être très précieux pour étudier les relations entre épigénèse et fonctionnement des gènes,

- les clones adultes issus d'un même génotype étant par définition (aux mutations en cours de culture près) des copies d'un même génome (génocopies), on peut les utiliser pour s'affranchir des différences alléliques dans l'étude de caractères multigéniques tout en maintenant des différences épigénétiques élevées puisque ces différences se manifestent surtout au cours du développement précoce. Les clones permettent de simplifier les dispositifs expérimentaux pour étudier l'origine 
épigénétique de la variabilité phénotypique de caractères.

Les séquences ADN les plus sujettes aux variations de méthylation sont les séquences répétées de cytosine et de guanine formant les îlots $\mathrm{CpG}$ et répartis sur tout le génome, mais aussi des régions spécifiques du génome puisque les séquences régulatrices des gènes à expression tissu-spécifique sont en général méthylées sauf dans le tissu concerné. L'utilisation de clones permettrait d'étudier précisément les différences de méthylation sur certains ilôts entre individus et de les corréler à des mesures phénotypiques. La connaissance de l'impact des régulations épigénétiques de l'expression permettrait une étude plus fine du déterminisme génétique de ces caractères phénotypiques.

\section{b) Application pour les races en voie de disparition}

Un grand nombre de races d'animaux d'élevage voient leurs effectifs diminuer dangereusement et sont menacées d'extinction (1350 races selon la FAO 2000). Le clonage somatique peut être un outil supplémentaire pour restaurer un certain nombre de génotypes qu'il faut ensuite reproduire par voie sexuée pour recréer un minimum de diversité. Des exemples commencent à exister. En Nouvelle-Zélande, la race bovine «Enderby Island» vivant en autarcie sur une île déserte sub-antarctique avait pratiquement disparu à la suite d'une épizootie. En 1999, il ne restait plus qu'une seule femelle âgée et des cellules de cumulus récupérées sur cet animal lors d'une tentative de ponction d'ovocytes pour la fécondation in vitro, ont été utilisées pour le clonage. Une vingtaine de clones de cette femelle ont pu être produites (Wells et al 1998) et mises à la reproduction par IA avec le sperme de 9 taureaux de cette même race qui avait pu être mis en réserve avant l'épizootie. De la même façon en France, nous avons prélevé une biopsie de peau sur une des dernières vaches «Bleu de Bazougers», et cloné cet animal à titre expérimental pour en démontrer la faisabilité. Cette vache clonée maintenant adulte s'est développée normalement, a été inséminée et a donné naissance à 2 descendants après IA avec le sperme de l'un des taureaux conservés.

c) Clonage et conservation des espèces sauvages

Le transfert de noyaux somatiques issus de génotypes sauvages rares peut également être envisagé, mais dans ce cas la difficulté consiste à disposer d'ovules receveurs en grand nombre. Les ovocytes de la même espèce seront par définition très rares voire inaccessibles puisque l'espèce en question est menacée. Des essais sont actuellement en cours pour réaliser des transferts de noyaux interspécifiques, par exemple des transferts de cellules de bouquetin du désert (Ovis canadiensis mexicana) dans des ovocytes de brebis domestique (Williams et al 2002). De même des cellules de granulosa prélevées post mortem sur un mouflon ont été transférées dans des cytoplasmes ovins et ont abouti à la naissance d'un mouflon cloné (Loi et al 2001). Un daim a été cloné pour la première fois au Texas (cité par Campbell et al 2005).

Des fibroblastes issus d'antilopes des montagnes Bongo (Tragelaphus eurycerus isaaci) utilisés en transfert de noyaux dans des ovocytes de bovin peuvent donner des blastocystes in vitro (Lee et al 2002). De nombreuses difficultés subsistent pour obtenir des développements à terme in vivo après transfert de noyaux interspécifique. Même si un clone de bovidé Gaur a pu se développer jusqu'à la naissance dans une vache porteuse (Hammer et al 2001) le jeune n'était pas viable et il importe de mieux comprendre les mécanismes de reprogrammation du noyau dans un cytoplasme hétérologue afin de mieux maitriser cet aspect. La difficulté peut aussi venir des mères porteuses qui doivent être le plus proche possible de l'espèce dont on veut obtenir des clones. Un programme scientifique entre chercheurs de I'INRA, du CIRAD et du Vietnam a été mis en place pour tester les possibilités de conserver une espèce de bovidé extrêmement rare des hauts plateaux du Vietnam, le Saola. Des données de phylogénie moléculaire et de physiologie du développement devront être analysées pour déterminer quelle famille de bovinae pourra être utilisée comme mères porteuses.

\section{3 / Clonage et acceptabilité sociale}

Le clonage animal est devenu un sujet sensible qui doit prendre en compte tous les aspects éthiques depuis l'expérimentation animale, le bien-être, la légitimité des recherches engagées et la sensibilité de l'opinion vis-à-vis des applications potentielles. Le clonage a été l'un des premiers sujets de saisine du comité d'Ethique et de précaution de l'INRA (COMEPRA) dès 1999 (rap- port COMEPRA du 26 juin 2000). Depuis, de nombreux débats sont organisés à tous les niveaux (Laboratoire, Département de recherche, organisations professionnelles d'élevage). L'Unité de Biologie du Développement et Reproduction de Jouy-en-Josas reste en France la seule formation de recherche qui étudie, en collaboration étroite avec des professionnels de l'élevage (UNCEIA) le clonage des ruminants. Cette unité de recherche fait partie du département PHASE (Physiologie Animale et Système d'Elevage) de l'INRA qui a proposé de regrouper les recherches sur le clonage (et la transgénèse animale) en trois domaines selon l'objectif auquel elles s'adressent : la compréhension du rôle des gènes, l'innovation thérapeutique et l'innovation agronomique. Les règles proposées pour valider les projets de recherche sont différenciées selon une grille d'évaluation qui prend notamment en compte des critères d'acceptation par la société. Cette démarche constitue une première étape vers la mise en place de procédures originales associant, dès l'élaboration d'un programme de recherche "sensible», des scientifiques de différentes disciplines, sciences biologiques et sciences humaines. La question essentielle du vivant naturel et artificiel posée par les clones fait l'objet d'un travail en commun avec des philosophes, dans le cadre d'un programme du Ministère de la Recherche. Ces travaux devront s'ouvrir à d'autres composantes de la société et contribuer ainsi à renforcer, à partir de questionnements très concrets, l'information et l'éducation du citoyen sur les biotechnologies (Ouedraogo 2004).

La perception par le public du clonage associé à la transgénèse est différente selon l'usage que l'on prévoit d'en faire. Le développement de nouveaux vaccins est largement accepté au contraire de la production d'animaux d'élevage aux capacités de croissance accrues. Des instances sont déjà en place en Europe pour évaluer le questionnement éthique autour des manipulations du génome (Centre for Bioethics and Risk Assessment-CeBRA www.sl.kvl.dk/cloninginpublic). La production d'animaux transgéniques est à l'heure actuelle peu efficace et coûte cher. L'un des aspects à prendre en compte est donc de savoir si à long terme, ce coût est en rapport avec une productivité accrue, une augmentation du bénéfice pour le consommateur, ou idéalement les deux. 


\section{Conclusions}

Le clonage somatique est encore une biotechnologie en phase de recherche et en plein devenir. Il a connu des progrès importants au cours des dernières années et l'on peut considérer que chez les bovins l'efficacité du clonage en termes de veaux nés a triplé en l'espace de 5 ans. Les connaissances sur les animaux clonés deviennent chaque jour plus importantes à travers le monde et les recherches développées à l'INRA sur les bovins clonés et leur descendance contribuent à l'étude des effets à long terme associés aux différentes étapes du transfert de noyaux.

La réflexion sur l'utilisation de cette biotechnologie en émergence est très active à la fois dans le secteur de la recherche, des organisations professionnelles d'élevage, ou du citoyen consommateur. Il importe de bien faire la distinction entre animaux clonés et animaux génétiquement modifiés car ils ont une acceptabilité sociétale et des applications différentes.

Les recherches essentielles visent à développer des modèles d'étude de maladies, la production de molécules pharmaceutiques et la production d'aliments économiques et de qualité. Ce faisant, ces recherches prennent en compte le bien-être animal, et les questions éthiques. Dans cette optique, nous portons une grande attention à la période foetale dans nos recherches sur le clonage afin de mieux comprendre et de limiter les pathologies observées à cette période. Une vigilance accrue est demandée aux chercheurs lorsqu'ils prévoient de conduire des investigations dans le domaine des biotechnologies. L'utilisation des nouvelles méthodes de production d'animaux génétiquement sélectionnés ou manipulés devra se faire de concert avec une bonne maitrise de la gestion de la diversité des espèces et de l'environnement. Une coordination des actions au niveau européen permettrait de développer les recherches fondamentales sur le début du développement embryonnaire, d'optimiser l'efficacité du clonage, d'évaluer les applications agronomiques potentielles et de développer un programme de recherches international sur les risques associés à cette biotechnologie.

\section{Références}

Adenot P., Mercier Y., Renard J.P., Thompson E., 1997. Differential H4 acetylation of paternal and maternal chromatin precedes DNA replication and differential transcriptional activity in pronuclei of 1-cell mouse embryos. Development, 124, 4615-4625.

Adenot P.G., Campion E., Legouy E., Allis C.D., Dimitrov S., Renard J., Thompson E.M., 2000. Somatic linker histone H1 is present throughout mouse embryogenesis and is not replaced by variant $\mathrm{H} 1$ degrees. J. Cell Sci., 113, 2897-2907.

Baldassare H., Karatzas C.N., 2004. Advanced assisted reproduction technologies (ART) in goats. Anim. Reprod. Sci., 82-83, 255-266.

Barker D.J.P., Eriksson J.G., Forsen T., Osmond C., 2002. Fetal origins of adult disease: strength of effects and biological basis. Int. J. Epidemiol., 31, 1235-1239.

Beaujean N., Martin C., Debey P., Renard J.P., 2005. Reprogrammation et épigénèse. Médecine/Science, 4, 412-421.

Behboodi E., Ayres S.L., Reggio B.C., O'Coin M.D., Gavin W.G., Denniston R.S., Landry A.M., Meade H.M., Echelard Y., 2002. Pregnancy profile and health status of goats derived by somatic cell nuclear transfer. Theriogenology, 57, 395.

Berthelot V., Bas P., Heyman Y., ChavattePalmer P., 2004. Comparaison de la composition en acides gras du muscle et du lait de vaches Holstein issues de clonage somatique et d'animaux issus d'insémination artificielle. Renc. Rech. Rum., 11, 394.

Boerjan, M.L., den Daas J.H.G., Dieleman S.J., 2000. Embryonic origins of health: long term Effects of IVF in human and livestock. Theriogenology, 53, 537-547.

Bondioli, K.R., Westhusin M.E., Looney C.R., 1990. Production of identical bovine offspring by nuclear transfer. Theriogenology, 33, 165-174.

Bordignon V., Clarke H.J., Smith L.C., 2001. Factors controlling the loss of immunoreactive somatic histone $\mathrm{H} 1$ from blastomere nuclei in oocyte cytoplasm: a potential marker of nuclear reprogramming. Dev. Biol., 233, 192-203.

Bourc'his D., LeBouahis B.D., Patin D., Niveleau A., Comizzoli P., Renard J.P., ViegasPéquignot E., 2001. Delayed and incomplete reprogramming of chromosome methylation patterns in bovine cloned embryos. Cur. Biol., 11, 1542-1546.

Bousquet D., Blondin P., 2004. Potential uses of cloning in breeding schemes: dairy cattle. Cloning Stem Cells, 6, 190-197.

Campbell K.H.S., Alberio R., Choi I., Fisher P., Kelly R.D.W., Lee J.H., Maalouf W., 2005. Cloning: eight years after Dolly. Reprod. Dom. Anim., 40, 256-268.

Chavatte-Palmer P., Heyman Y., Richard C., Monget P., LeBourhis D., Kann G., Chilliard Y., Vignon X., Renard J.P., 2002. Clinical, hormonal, and hematologic characteristics of bovine calves derived from nuclei from somatic cells. Biol. Reprod., 66, 1596-1603.

Chavatte-Palmer P., Constant F., Heyman Y., Laigre P., 2003. Images échographiques de gestations pathologiques après clonage, exemples du syndrome du gros veau. Journées Nationales des Groupements Techniques Vétérinaires., Nantes, France, 665-672.

Chavatte-Palmer P., Rémy D., Cordonnier N., Richard C., Issenmann H., Laigre P., Heyman Y., Mialot J.P., 2004. Health status of cloned cattle at different ages. Cloning Stem Cells, 6, 92-98.

Chavatte-Palmer P., Rémy D., Richard C., Issenman H., Mialot J.P., 2004. Haematological and biochemical measurements of cloned calves during the two first months of life. World Buiatry Congress, Quebec, Canada. 139-140.

Chesné P., Perreau C., Lavergne Y., Poulin N., Baril G., Capo D., Bouttier A., Rougheol C., Cognie Y., Vignon X., Mermillod P., Heyman Y., 2003. Birth of live offspring from cultured nuclear transferred embryos in goats. $19^{\text {th }}$ AETE Meeting, Rostock, Allemagne, 144.

Cibelli J.B., Stice S., Golueke P.J., Kane J.J.,
Jerry J., Blackwell C., Ponce de Leon F.A., Robl J.L., 1998. Cloned transgenic calves produced from non-quiescent fetal fibroblasts. Science, 280, 1256-1258.

Colleau J.J., Heyman Y., Renard J.P., 1998. Les biotechnologies de la reproduction chez les bovins et leurs applications réelles ou potentielles en sélection. INRA Prod. Anim., 11, 41-56.

Drake J.W., Charlesworth B., Charlesworth D., Crow J.F., 1998. Rates of spontaneous mutation. Genetics, 148, 1667-1686.

De Montera B., Boulanger L., Taourit S. Renard J.P., Eggen A., 2004. Genetic identity of clones and methods to expore DNA. Cloning Stem Cell, 6, 133-139.

De Sousa P.A., Walker S., King T.J., Young L.E., Harkness L., Ritchie W.A., Travers A., Ferrier P., Wilmut I., 2001. Evaluation of gestational deficiencies in cloned sheep fetuses and placentae. Biol. Reprod., 65, 23-30.

Denning C., Burl S., Ainslie A., Bracken J., Dinnyes A., Fletcher J., King T., Ritchie M., Ritchie W.A., Rollo M., de Sousa P., Travers A., Wilmut I., Clark A. J., 2001. Deletion of the alpha $(1,3)$ galactosyl transferase (GGTA1) gene and the prion protein $(\mathrm{PrP})$ gene in sheep. Nat. Biotechnol., 19, 559-562.

Faber D.C., Ferre L.B., Metzger J., Robl J.M., Kasinathan P., 2004. Agro-economic impact of cattle cloning. Cloning Stem Cells, 6, 198-207.

FAO, 2000. World Watch List for domestic animal diversity. www.fao.org.

Fleming T.P., Kwong W.Y., Porter R., Ursell E., Fesenko I., Wilkins A., Miller D.J., Watkins A.J., J. Eckert J., 2004. The embryo and its future. Biol. Reprod., 71, 1046-1054.

Forsberg E.J., Strelchenko N.S., Augenstein M.L., Betthauser J.M., Childs L.A., Eilertsen K.J. Enos J.M., Forsythe T.M., Golueke P.J., Koppang R.W., Lange G., Lesmeister T.L., Mallon K.S., Mell G.D., Misica P.M., Pace M.M., PfisterGenskow M., Voelker G.R., Watt S.R., Bishop M.D., 2002. Production of cloned cattle from in vitro systems. Biol. Reprod., 67, 327-333. 
Gartner K., Baunack E., 1981. Is the similarity of monozygotic twins due to genetic factors alone? Nature, 292, 646-647.

Gauthier M., Pierson J., Drolet M., Bhatia B., Baldassarre H., Keefer C.L., 2001. Sexual maturation and fertility of male nigerian Dwarf Goat (Capra hircus) clones produced by somatic cell nuclear transfer. Cloning Stem Cells, 3, 151-155.

Georges M., Charlier C., Cockett N., 2003. The callipyge locus: evidence for the trans interaction of reciprocally imprinted genes. Trends Genet., 19, 248-252.

Gibbons J., Arat S., Rzucidlo J., Miyoshi K., Waltenburg R., Respess D., Venable A., Stice S., 2002. Enhanced survivability of cloned calves derived from roscovitine-treated adult somatic cells. Biol. Reprod., 66, 895-900.

Govoni K.E., Tian X.C., Kazmer G.W., Taneja M., Enright B.P., Rivard A.L., Yang X., Zinn S.A., 2002. Age-related changes of the somatotropic axis in cloned Holstein calves. Biol. Reprod., 66, 1293-1298.

Hammer C.J., Tyler H.D., Loskutoff N.M., Armstrong D.L., Funk D.J., Lindsey B.R., Simmons L.G., 2001. Compromised development of calves (Bos gaurus) derived from in vitro-generated embryos and transferred interspecifically into domestic cattle (Bos taurus). Theriogenology, 55, 1447-1455.

Hiendleder S., Zakhartchenko V., Wolf E., 2005. Mitochondria and the success of somatic cell nuclear transfer cloning: from nuclear-mitochondrial interactions to mitochondrial complementation and mitochondrial DNA recombinaison. Reprod. Fertil. Dev., 17, 69-83.

Heyman Y., Chavatte-Palmer P., LeBourhis D., Camous S., Vignon X., Renard J.P., 2002. Frequency and occurrence of late-gestation losses from cattle cloned embryos. Biol. Reprod., $66,6-13$.

Heyman Y., Richard C., Rodriguez-Martinez H., Lazzari G., Chavatte-Palmer P., Vignon X., Galli C., 2004. Zootechnical performance of cloned cattle and offspring: preliminary results. Cloning Stem Cells, 6, 111-120.

Hill J.R., Roussel A.J., Cibelli J.B., Edwards J.F., Hooper N.L., Miller M.W., Thompson J.A., Looney C.R., Westhusin M.E., Robl J.M., Stice S.L.,1999. Clinical and pathologic features of cloned transgenic calves and fetuses (13 cases studies). Theriogenology, 51, 14511465 .

Hill J.R., Burghardt R.C., Jones K., Long C.R., Looney C.R., Shin T., Spencer T.E., Thompson J.A., Winger Q.A., Westhusin M.E., 2000. Evidence for placental abnormality as the major cause of mortality in first-trimester somatic cell cloned bovine fetuses. Biol. Reprod., 63, 1787-1794.

Hill J.R., Chavatte-Palmer P., 2002. Pregnancy and neonatal care of cloned animals. Principles of cloning. J. Cibelli. San Diego, Academic Press, 247-266.

Hill JR., Schlafer D.H, Fisher P., Davies C.J., 2002. Abnormal expression of trophoblast major histocompatibility complex class I antigens in cloned bovine pregnancies is associated with a pronounced endometrial lymphocytic response. Biol. Reprod., 67, 55-63.

Kang Y.K., Park J.S., Koo D.B., Choi Y.H., Kim S.U., Lee K.K., Han Y.M., 2002. Limited demethylation leaves mosaic-type methylation states in cloned bovine pre-implantation embryos. Embo J., 21, 1092-1100.
Kasinathan P., Knott J.G., J.G. Moreira J.G., Burnside A.S., Joseph Jerry D., Robl J.M., 2001 Effect of fibroblast donor cell age and cell cycle on development of bovine nuclear transfer embryos in vitro. Biol. Reprod., 64, 1487-1493.

Kato Y., Tani T., Tsunoda Y., 2000. Cloning of calves from various somatic cell types of male and female adult, newborn and fetal cows. J. Reprod. Fertil., 120, 231-237.

Keefer C., Lazaris A., Keyston R., Begin I., Bhatia B., Wang B., Bilodeau A., Gauthier M., Zhou J., Leduc M., 2002. Production of cloned transgenic goats as a potential source for human pharmaceuticals. Theriogenology, 57, 422.

Kubota C., Yamakuchi H., Todoroki J., Mizoshita K., Tabara N., Barber M., Yang X., 2000. Six cloned calves produced from adult fibroblast cells after long-term culture. PNAS, 97.

Kuroiwa Y;, Kasinathan P., Matsushita H., Sathiyaselan J., Sullivan E.J., Kakitani M. Tomizuka K., Ishida I., Robl J.M., 2004. Sequential targeting of the genes encoding immunoglobulin-mu and prion protein in cattle. Nat. Genet., 36, 775-780.

Kwong W., Wild A., Roberts P., Willis A., Fleming T., 2000. Maternal undernutrition during the preimplantation period of rat development causes blastocyst abnormalities and programming of postnatal hypertension. Development, 127, 4195-4202.

Laigre P., Chavatte-Palmer P., Vignon X., Heyman Y., 2004. Suivi échographique de gestations bovines après transfert d'embryons clonés. Renc. Rech. Rum., 11, 393.

Lanza R.P., Cibelli J.B., Faber D., Sweeney R.W., Henderson B., Nevala W., West M.D., Wettstein P.J., 2001. Cloned cattle can be healthy and normal. Science, 294, 1893-1894.

Lee B., Wirtu G., Andrews J., Poole K., Dresser B., Bavister B., 2002. Blastocyst development after interspecies nuclear transfer of montain bongo antelope somatic cells into bovine oocytes. Theriogenology, 57, 586 .

Lee R.S.F., Peterson A.J., Donnison M.J., Ravelich S., Ledgard A.M., Li N., Oliver J.E., Miller A.L., Tucker F.C., Breier B., Wells D.N., 2004. Cloned Cattle fetuses with the same nuclear genetics are more variable than contemporary half-siblings resulting from artificial insemination and exhibit fetal and placental growth deregulation even in the first trimester. Biol. Reprod., 70, 1-11.

Li G.P.., White K.L., Bunch T.D., 2004. Review of enucleation methods and procedures used in animal cloning: state of the art. Cloning Stem Cells, 6, 5-13.

Loi P., Ptak G., Barboni B., Fulka J.Jr., Cappai P., Clinton M., 2001. Genetic rescue of an endangered mammal by cross-species nuclear transfer using post-mortem somatic cells. Nat. Biotechnol., 19, 962-964.

Lonergan P., Carolan C., Van Langendonckt A., Donnay I., Khatir H., Mermillod P., 1996. Role of epidermal growth factor in bovine oocyte maturation and preimplantation development in vitro. Biol. Reprod., 54, 1420-1429.

McCreath K.J., Howcroft J., Campbell K.H., Colman A., Schnieke A.E., Kind A. J., 2000. Production of gene-targeted sheep by nuclear transfer from cultured somatic cells. Nature, 405 , 1066-1069.

Mermillod P., LeBourhis D., Lonergan P., Khatir H., Heyman Y., 1998. Assessment of cytoplasmic competence of prepubertal calf oocytes by use of nuclear transfer Theriogenology, 49, 187 abst.

Miyashita N., Shiga K., Yonai M., Kaneyama K., Kobayashi S., Kojima T., Goto Y., Kishi M. Aso H, Suzuki T., Sakaguchi M., Nagai T., 2002. Remarkable differences in telomere lengths among cloned cattle derived from different cell types. Biol. Reprod., 66, 1649-1655.

Miyashita, N., Shiga K., Fujita T., Umeki H., Sato W., Suzuki T., Nagai T., 2003. Normal telomere lengths of spermatozoa in somatic cellcloned bulls. Theriogenology, 59, 1557-1565.

Norman H.D., Walsh M.K., 2004. Performance of dairy cattle clones and evaluation of their milk composition. Cloning Stem Cells, 6, 157-164.

Oback B., Wells D.N., 2003. Cloning cattle. Cloning Stem Cells, 5, 243-256.

Ogura A., Inoue K., Ogonuki N., Lee J., Kohda T., Ishino F., 2002. Phenotypic effects of somatic cell cloning in the mouse. Cloning Stem Cells, 4, 397-405.

Ouedraogo A.P., 2004. Public perceptions of reproductive biotechnologies: the case of farm animal breeding and reproduction in France and the United Kingdom. Cloning Stem Cells, 6, 182-189.

Ozil J.P., Markoulaki S., Toth S., Matson S., Banrezes B., Knott J.G., Schultz R.M., Huneau D., Ducibella T., 2005 Egg activation events are regulated by the duration of a sustained $[\mathrm{Ca} 2+]$ cyt signal in the mouse. Dev. Biol., 282, $39-54$

Pace M.M., Augenstein M.L., Betthauser J.M., Childs L.A., Eilertsen K.J., Enos J.M., Forsberg E.J., Golueke P.J., Graber D.F., Kemper J.C., Koppang R.W., Lange G., Lesmeister T.L., Mallon K.S., Mell G.D., Misica P.M., PfisterGenskow M., Strelchenko N.S., Voelker G.R., Watt S.R., Bishop M.D., 2002. Ontogeny of cloned cattle to lactation. Biol. Reprod., 67, 334-339.

Pailhoux E., Vigier B., Chaffaux S., Servel N., Taourit S., Furet J.P., Fellous M., Grosclaude F., Cribiu E.P., Cotinot C., Vaiman D., 2001. A 11.7$\mathrm{kb}$ deletion triggers intersexuality and polledness in goats. Nat. Genet., 29, 453-458.

Powell A.M., Talbot N.C., Wells K.D., Kerr D.E., Pursel V.G., Wall R.J., 2004. Cell donor influences success of producing cattle by somatic cell nuclear transfer. Biol. Reprod., 71, 210-216.

Quintanilla R., Milan D., Bidanel J.P., 2002. A further look at quantitative trait loci affecting growth and fatness in a cross between Meishan and Large White pig populations. Genet. Sel. Evol., 34, 193-210.

Ravelich S.R., Breier B.H., Reddy S., Keelan J.A., Wells D.N., Peterson A.J., Lee R.S.F., 2004. Insulin-Like Growth Factor-I and Binding Proteins 1, 2, and 3 in bovine nuclear transfer pregnancies. Biol. Reprod., 70, 430-438.

Reggio B.C., Green H.L., Sansinena M., Chen L.H., Behboodi E., Denniston R.S., Echelard Y., Godke R.A., 2002. Production of cloned transgenic goats as a potential source for human pharmaceuticals. Theriogenology, 57, 445.

Renard J.P., Chastant S., Chesné P., Richard C., Marchal J., Cordonnier N., Chavatte-Palmer P., Vignon X., 1999. Lymphoid hypoplasia and somatic cloning. The Lancet, 353, 1489-1491.

Renard J.P. Vignon X., 2001. Le clonage animal. La reproduction chez les mammifères et l'Homme. C. Thibault. M. C. Levasseur, INRA Ellipses (Ed), 390-409. 
Renard J.P., Zhou Q., LeBourhis D., ChavattePalmer P., Hue I., Heyman Y., Vignon X., 2002. Nuclear transfer technologies: between successes and doubts. Theriogenology, 57, 203-222.

Schnieke A.E., Kind A.J., Ritchie W.A., Mycock K., Scott A.R., Ritchie M., Wilmut I., Colman A., Campbell K.H. , 1997. Human factor IX transgenic sheep produced by transfer of nuclei from transfected fetal fibroblasts. Science, 278, 2130-2133.

Scott D., 2005. Workshop on Animal Cloning: Technology, applications and ethics, IPTS Séville, Espagne, 9-10 June 2005.

Shiga K., Umeki H., Shimura H., Fujita T., Watanabe S., Nagai T., 2005. Growth and fertility of bulls cloned from the somatic cells of an aged and infertile bull. Theriogenology, 64, 334343.

Shimozawa N., Ono Y., Kimoto S., Hioki K., Araki Y., Shinkai Y., Kono T., Ito M., 2002. Abnormalities in cloned mice are not transmitted to the progeny. Genesis, 34, 203-7.

Smith L.C., Murphy B.D., 2004 Genetic and epigenetic aspects of cloning and potential effects on offspring of cloned mammals. Cloning Stem Cell, 6, 126-132.

Szeto I.Y., Barton S., Keverne E.B., Surani A., 2004. Analysis of imprinted murine $<\mathrm{i}>\operatorname{Peg} 3</ \mathrm{i}>$ locus in transgenic mice. Mammalian Genome, $15,284-295$

Takeda K., Akagi S., Kaneyama K., Kojima T., Takahashi S., Imai H., Yamanaka M., Onishi A., Hanada H.2 2003. Proliferation of donor mitochondrial DNA in nuclear transfer calves (Bos taurus) derived from cumulus cells. Mol. Reprod.Dev., 64, 429-437.

Tamashiro K.L., Wakayama T., Akutsu H., Yamazaki Y., Lachey J.L., Wortman M.D, Seeley R.J., D'Alessio D.A., Woods S.C., Yanagimachi R., Sakai R.R., 2002. Cloned mice have an obese phenotype not transmitted to their offspring. Nat.Med., 8, 262-267.

Tamassia M., Heyman Y., Lavergne Y., Richard C., Gelin V., Renard J.P., ChastantMaillard S., 2003. Evidence of oocyte donor cow effect over oocyte production and embryo development in vitro. Reproduction, 126, 629-637.

Tian X.C., Kubota C., Sakashita K., Izaike Y., Okano R., Tabara N., Curchoe C., Jacob L., Zhang Y., Smith S., Bormann C., Xu J., Sato M.,
Andrew S., Yang X., 2005. Meat and milk compositions of bovine clones. PNAS, 102, 6261-6266.

Tomé D., Dubarry M., Fromentin G., 2004. Nutritional value of milk and meat products derived from cloning. Cloning Stem Cells, 6, 172-177.

Tsunoda Y., Kato Y., 2002. Recent progress and problems in animal cloning. Differentiation, $69,158-161$.

Vignon X., Chesné P., Lebourhis D., Fléchon J.E., Heyman Y., Renard J.P., 1998. Developmental potential of bovine embryos reconstructed with enucleated matured oocytes fused with cultured somatic cells. C. R. Acad. Sci. Paris, 321, 735-745.

Vignon X., Zhou Q., Renard J.P., 2002. Chromatin as a regulative architecture of the early developmental functions of mammalian embryos after fertilization or nuclear transfer Cloning Stem Cells, .4, 363-377.

Vignon X., Le Bourhis D., Laloy E., Lavergne Y., Servely J.L., Richard C., Renard J.P., Heyman Y., 2003. A comparison on the development of bovine embryons cloned from fibroblasts of two different genetic origins. Proc. AETE, Rostock, Allemagne, 218.

Walker S.K., Hartwich K.M., Seamark R.F., 1996. The production of unusually large offspring following embryo manipulation: concepts and challenges. Theriogenology, 45, 111-120.

Walsh M. K., Lucey J.A., GovindasamyLucey S., Pace M.M., Bishop M.D., 2003. Comparison of milk produced by cows cloned by nuclear transfer with milk from non-cloned cows. Cloning Stem Cells, 5, 213-219.

Wells D.N., 2003. Cloning in livestock agriculture. Reproduction, Suppl. 61, 131-150.

Wells D.N., Misica P.M., Tervit H.R., Vivanco W.H., 1998. Adult somatic cell nuclear transfer is used to preserve the last surviving cow of Enderby Island cattle breed. Reprod. Fertil. Dev., $10,369-378$

Wells D.N., Forsyth J.T., McMillan V., Oback B., 2004. The health of somatic cell cloned cattle and their offspring. Cloning Stem Cells, 6, 101110 .

Whitelaw B.,2005. Workshop on Animal Cloning : technology, application and ethics. IPTS Séville, Espagne, 9-10 June 2005.
Willadsen S.M., 1986. Nuclear transplantation in sheep embryos. Nature, 320, 63-65.

Williams B., Shin T., Liu L., Flores-Foxworth G., Romano J., Rugila J., Dean D., Burghardt R., Westhusin M., Kraemer D., 2002. Interspecies nuclear transfer of desert bighorn. Theriogenology, 57, 457.

Wilmut I., Schnieke A.E., McWhir J., Kind A.J., Campbell K.H.S., 1997. Viable offspring derived from fetal and adult mammalian cells. Nature, 385, 810-813.

Wrenzycki C., Herrmann D., Lucas-Hahn A., Korsawe K., Lemme E., Niemann H., 2005. Messenger RNA expression patterns in bovine embryos derived from in vitro procedures and their implications for development. Reprod. Fertil. Dev., 17, 23-25.

Yang L., Chavatte-Palmer P., Kubota C., O'Neill M., Hoaglang T., Renard J.P., Taneja M., Yang X., Tian X.C., 2005. Expression of imprinted genes is aberrant in deceased newborn cloned calves and relatively normal in surviving adult clones. Mol. Reprod. Dev., 71, 431438.

Young L.E., Fairnburn H.R., 2000. Improving the safety of embryo technologies:possible role of genomic imprinting. Theriogenology, 53, 627648.

Young L.E., Sinclair K.D., Wilmut I., 1998. Large offspring syndrome in cattle and sheep. Rev. Reprod., 3, 155-163.

Zakhartchenko V., Alberio R., Stojkovic M., Prelle K., Schernthaner W., Stojkovic P., Wenigerkind H., Wanke R., Düchler M., Steinborn R., Mueller M., Brem G., Wolf E., 1999. Adult cloning in cattle: Potential of nuclei from a permanent cell line and from primary cultures. Mol. Reprod. Dev., 54, 264-72.

Zakhartchenko V., Durcova-Hills G., Stojkovic M., Schernthaner W., Prelle K., Steinborn R., Muller M., Brem G., Wolf E., 1999. Effects of serum starvation and re-cloning on the efficiency of nuclear transfer using bovine fetal fibroblasts. J. Reprod. Fert., 115, 325331.

\section{Résumé}

Parmi les récentes biotechnologies de la reproduction chez les mammifères d'élevage, le clonage par transfert de noyaux somatiques constitue un pas en avant depuis la naissance de la brebis Dolly. Cet article fait le point sur les résultats actuels obtenus dans le monde chez les bovins et les petits ruminants, les limites de la technique et les applications potentielles. L'efficacité globale du clonage (nombre de jeunes nés /nombre d'embryons reconstitués) reste encore faible $(\leq$ à $7 \%)$, mais elle progresse régulièrement. Elle est cependant limitée par l'existence de mortalités embryonnaires et de physiopathologies foetales importantes après transplantation des embryons clonés dans des femelles porteuses. Après leur naissance, les bovins clonés font l'objet d'un programme de recherches à l'INRA pour évaluer leur santé, leurs performances à l'âge adulte ainsi que les éventuels risques associés au clonage. Malgré l'existence de différentes barrières biologiques encore mal maîtrisées, plusieurs applications du clonage peuvent être envisagées dont la production d' animaux modèles de maladies, la contribution à la sélection bovine, la reproduction de génotypes rares, ou bien, l'association avec la transgénèse pour des utilisations à des fins biomédicales. Les recherches en cours prennent en compte la réflexion éthique et la perception sociale du clonage animal. 


\begin{abstract}
Animal somatic cloning: state of the art in cattle and small ruminants

Among the recent reproductive biotechnologies for domestic mammals, somatic cell nuclear transfer is a new step forward, since the birth of Dolly the sheep. This article reports the current results obtained worldwide in cattle, sheep and goats, the limits of the technique and some potential applications. The overall efficiency (nb of young born/nb of reconstructed embryos) remains low ( $\leq 7 \%$ ), but has been progressing. Embryonic mortality and important foetal physiopathologies are limiting factors. A research programme on bovine clones at INRA is aimed at the evaluation of the clone's health, their zootechnical performances as well as potential risks related to cloning. Despite some uncontrolled biological barriers, several applications of somatic cloning are being developed such as animal models for diseases, new tools for genetic selection, reproduction of rare genotypes or association with transgenesis for biomedical use. Current research takes into account the ethical aspects and societal concerns about animal cloning.
\end{abstract}

HEYMAN Y., CHAVATTE-PALMER P., VIGNON X., RICHARD C., RENARD J.-P., 2005. Le clonage somatique : un état des lieux chez les bovins et les petits ruminants. INRA Prod. Anim., 18, 339-354. 